\title{
Adsorptive Separation of Brilliant Green Dye from Water by Tartaric Acid-Treated Holarrhena antidysenterica and Citrullus colocynthis Biowaste
}

\author{
Sumaira Basharat, ${ }^{1}$ Rabia Rehman $\mathbb{D}^{1},{ }^{1}$ and Liviu Mitu $\mathbb{D}^{2}$ \\ ${ }^{1}$ School of Chemistry, University of the Punjab, Lahore 54590, Pakistan \\ ${ }^{2}$ Department of Nature Sciences, University of Pitesti, Pitesti 110040, Romania \\ Correspondence should be addressed to Rabia Rehman; grinorganic@yahoo.com and Liviu Mitu; ktm7ro@yahoo.com
}

Received 19 January 2021; Revised 2 March 2021; Accepted 12 March 2021; Published 18 March 2021

Academic Editor: Vinod Kumar Tiwari

Copyright (c) 2021 Sumaira Basharat et al. This is an open access article distributed under the Creative Commons Attribution License, which permits unrestricted use, distribution, and reproduction in any medium, provided the original work is properly cited.

Holarrhena antidysenterica $(\mathrm{Ha})$ and Citrullus colocynthis $(\mathrm{Cc})$ biowaste from indigenous Pakistan resources was used to remove toxic brilliant green (BG) dye from aqueous solutions in a batch mode. Tartaric acid chemical modification gave promising results than the nonmodified forms of biowaste. Surface characterization was carried out by FT-IR and SEM. The optimum conditions for (BG) dye elimination by Ha-tartaric acid modified (Ha-Ta) were $1.8 \mathrm{~g}, 45$ minutes, $4.0 \mathrm{pH} ; 40^{\circ} \mathrm{C}$, and $100 \mathrm{rpm}$ and with Cc-tartaric acid modified (Cc-Ta) were $1.6 \mathrm{~g}, 45$ minutes, $6.0 \mathrm{pH} ; 40^{\circ} \mathrm{C}$, and $150 \mathrm{rpm}$ dye solution shaking rate, which gave optimum results. Equilibrium data of raw and chemically modified biowaste followed the Langmuir model indicating monolayer chemisorption. $Q_{\max }$ values were found to be $55.24 \mathrm{mg} / \mathrm{g}, 112.35 \mathrm{mg} / \mathrm{g}, 50.50 \mathrm{mg} / \mathrm{g}$, and $79.36 \mathrm{mg} / \mathrm{g}$ for Ha, Ha-Ta, Cc, and Cc-Ta. Kinetics followed the pseudo-second-order kinetic model. Dye removal involved surface and intraparticle mode of diffusion. Thermodynamic studies proved the process to be spontaneous and exothermic one. The adsorbents can be effectively utilized for the removal of toxic basic dyes, such as BG from wastewaters.

\section{Introduction}

With the advent of modernization came great responsibilities to meet the needs of mankind. Increasing industrialization resulted in pollution of soils and water. Textile, paper, and leather industries discharge dyes directly into the water bodies without any pretreatment, leading to environmental concerns. Dissolution of particle charges in an aqueous medium categorizes dyes into anionic (acidic, direct, and reactive), cationic (basic), and nonionic (dispersed). In addition, cationic colorants are more hazardous than anionic ones $[1,2]$. Dyes are tolerant to microbial, chemical, and photochemical degradation. Their presence in minute amounts $(1 \mathrm{mg} / \mathrm{L})$ [3] poses allergic, mutational, and carcinogenic disabilities [4]. Classical methods such as precipitation, ozonation, coagulation, flocculation, ion exchange, and reverse osmosis [5] proved to be limited to smaller scale, poisonous sludge productivity, and expensive procedures, urging scientists to opt for new pathways [6]. Adsorption is favored upon them due to simple design, availability, maintenance, cost effectiveness, easy operation, and economic feasibility. It offers strong competitors against activated carbon, which is immensely utilized for its chemically active nature, higher specific surface area, larger pore volumes, and adsorption capacities [7], but when prepared from coal and lignocellulosic ingredients, it is ultraexorbitant and not ecofriendly $[8,9]$.

Adsorption is termed as removal of impurities (adsorbates) from the solid surface (adsorbent) by establishing strong bonding among the porous structure of the adsorbent surface and chelated entities, the adsorbate particles being eliminated from the bulk phase while moving from one phase to another crossing a barrier. Complexation is followed by ion exchange, hydrogen bonding, and pore 
diffusion $[10,11]$. Low-cost materials such as fallen leaves, bagasse, seeds, saw dust, fruit peels, and tree bark are used as adsorbents because of cheapness and availability.

Brilliant green (BG), a synthetic organic coloring agent, belonging to the triphenyl methane family is widely used in printing paper and textile industries [12]. It causes serious health issues, damaging renal tissues and the reproductive systems in humans. Its decomposition results in serious environmental damage by producing oxides of nitrogen and sulfur [13]. Recently, dye removal was performed by nanofibrous composites [14], photocatalysis [15], electrocoagulation [16], microwave-induced catalytic oxidation [17], biodegradation [17], membrane separation [4], advanced oxidation processes [18-21], and adsorption [22] techniques.

The adsorbents used are Holarrhena antidysenterica (Ha) and Citrullus colocynthis (Cc). H. antidysenterica (Inderajao) has many medical uses as a cure for dysentery, skin inflammations, osteoporosis, and rheumatism [23]. Various functional moieties [24] such as cellulose, hemicellulose, and lignin are present that encapsulate BG from wastewaters. C. colocynthis (Indrayan) cures breast cancer and diabetes and increases hair length [25] due to various natural products in it $[26,27]$.

The aim of this study is to utilize cheap biowaste from indigenous Pakistan resources. They are modified with tartaric acid $\left(\mathrm{C}_{4} \mathrm{H}_{6} \mathrm{O}_{6}\right)$, to remove toxic brilliant green dye from aqueous solutions. The raw and modified adsorbents are characterized by Fourier-transform infrared (FTIR) spectroscopy and scanning electron microscopy techniques. Batch adsorption studies were performed. Effects of various experimental parameters such as adsorbent dosages, $\mathrm{pH}$ effects, temperature studies, agitation rates, and contact times were investigated. Isothermal, kinetic, and thermodynamic studies were conducted for evaluation of the possible mechanism involved.

\section{Experimental Methods}

2.1. Collection of Biowaste. Ha and Cc biowastes were taken from markets of Lahore city, Pakistan. They were washed, dried in sunshine for 3-4 days, grounded, and stored in plastic jars after passing through 60 mesh sieves. The resultant product was soaked separately in $10 \%$ aqueous solution of tartaric acid for chemical modification, then filtered, and dried again prior to usage [27].

2.2. Chemicals and Instrumentation. Brilliant green (C.I. 42040), having molecular formula $\mathrm{C}_{27} \mathrm{H}_{33} \mathrm{~N}_{2} \mathrm{O}_{4} \mathrm{~S}$ and molecular weight $482.63 \mathrm{~g} \cdot \mathrm{mol}^{-1}$, was purchased from Merck (Germany) and used without further purification. $1000 \mathrm{mg} / \mathrm{L}$ stock solution was prepared by dissolving $1 \mathrm{~g}$ of BG per $1000 \mathrm{~mL}$ of distilled water. Further solutions used in this study were prepared by the diluting method. $0.1 \mathrm{M}$ solutions of hydrochloric acid and sodium hydroxide were utilized for the adjustment of $\mathrm{pH}$ value, utilizing the $\mathrm{pH}$ meter of Hanna Instruments (USA). The China Visible Spectrophotometer 720 determined the absorbance values at $\lambda_{\max } 628 \mathrm{~nm}$. The orbital shaker by Sky Line Analog was used. FourierTransform Infrared (FTIR) studies were performed with a Cary 630 FTIR spectrometer by Agilent technologies (USA), and for SEM analysis, the scanning electron microscope of Nova Nano 450 by Thermo Fischer Scientific (USA) was used.

2.3. Chemical Modifications on Adsorbents. $5 \mathrm{~g}$ adsorbents were added to $25 \mathrm{~mL}$ of acidic, basic, and chelating solvents and kept for 4 hours, resulting in filtrates, which when treated with BG dye gave the desired concentrations [28].

2.4. Biosorption Experiments. Batch scale studies were carried out for all the parameters. $100 \mathrm{~mL} \mathrm{BG}$ dye solutions were taken in $250 \mathrm{~mL}$ conical flasks at ambient temperatures. Fixed amounts of adsorbents were added to the dye solutions, then kept in rotary shakers, and agitated for 120 minutes. Various adsorption parameters such as adsorbent dose (0.2-2.2 g/L) [29], pH (1-10), specific contact time (5-60 minutes), agitation speeds $(20-200 \mathrm{rpm})$, and temperature $(303,313,323,333,343$, and $353 \mathrm{~K})$ were studied. Dye concentrations were monitored in filtrates, using a UV/ Vis spectrophotometer [30]. Percentage adsorption $(\% R)$ of dye was calculated (equation (1)), and the concentration of dye retained per unit mass of adsorbent is given by equation (2):

$$
\begin{aligned}
\% R & =C_{\mathrm{o}}-\frac{C_{\mathrm{e}}}{C_{\mathrm{o}}} \times 100, \\
q_{e} & =\left(C_{\mathrm{o}}-C_{\mathrm{e}}\right) \frac{V}{m},
\end{aligned}
$$

where $C_{\mathrm{o}}$ is the initial BG concentration $(\mathrm{mg} / \mathrm{L})$ and $C_{\mathrm{e}}$ is adsorption at equilibrium (mg/L). Also, " $q_{\mathrm{e}}$ " is the adsorption capacity of BG $(\mathrm{mg} / \mathrm{g})$, " $\mathrm{V}$ " is volume of the solution $(L)$, and " $m$ " is the amount of adsorbent used $(g)$ [31]. All experiments were performed twice, and average values were considered for this study.

2.5. Adsorption Kinetics. Rate of reaction is used for designing the mechanism of adsorption by finding conditions which best fit the models for a specific adsorbent-adsorbate system. Usually, systems follow Lagergren pseudo-first-order (equation (3)) or pseudo-second-order (equation (4)) kinetic models [32-35]:

$$
\begin{aligned}
\ln \left(q_{e}-q_{t}\right) & =\ln q_{e}-k_{1} t \\
\frac{t}{q_{t}} & =\frac{1}{K_{2} q_{e}^{2}}+\frac{t}{q_{e}},
\end{aligned}
$$

where $k_{1}\left(\mathrm{~h}^{-1}\right)$ and $k_{2}(\mathrm{~g} / \mathrm{mg} \cdot \mathrm{h})$ are rate constants for the pseudo-first order and pseudo-second order kinetic models, respectively, $q_{t}(\mathrm{mg} / \mathrm{g})$ is the amount of adsorbate adsorbed at time $t$, and $q_{e}$ (cal) $(\mathrm{mg} / \mathrm{g})$ is the amount of adsorbate adsorbed at the equilibrium state. Ho and Mckay explained the independency of particle diameter of the pseudo-rateconstant in chemically controlled dye uptake; hence, flow 
rate will be dependent upon the ionic concentrations of the solutions.

A plot between $\ln \left(q_{e}-q_{t}\right)$ and $t$ demonstrates a linear relation for the applicability of the pseudo-first-order model. $R^{2}$ figures are used for the evaluation of the best-fit model. Pseudo-second-order modeling is demonstrated by both basic and acidic dyes. A linear plot among $t / q$ and $t$ confirms this model.

The Elovich model represented in equation (5) gives energy variations exponentially related to fluctuations of adsorbent sites. Applied to gas adsorption on solid surfaces, this model implies multilayered adsorption [36, 37].

$$
q t=\frac{\ln (a \times b)}{b}+\frac{\ln t}{b} \text {. }
$$

Linear plots are obtained by plotting $\ln t$ (minutes) at the horizontal axis along with qt $\left(\mathrm{mgg}^{-1}\right)$ at the vertical axis. Significant checking of the kinetic modeling utilizes $P$ (percent-relative deviation) values (equation (6)). Lower values of $P$ indicate more appropriateness of kinetic data.

$$
P=\frac{100}{N} \sum\left\{\frac{q_{e(\exp )-q_{e(\mathrm{cal})}}}{q_{e(\exp )}}\right\},
$$

where $q_{\mathrm{e}}(\exp )(\mathrm{mg} / \mathrm{g})$ is the experimental biosorption capacity and $q_{\mathrm{e}}(\mathrm{mg} / \mathrm{g})$ is the calculated biosorption capacities and $N$ represents the number of estimations used for the experiment [38]. $25 \mathrm{mg} / \mathrm{L}$ dye solutions were selected at $298 \mathrm{~K}$ with all optimized conditions for BG retention kinetics. Absorbance values were seen at a difference of 5 minutes. The upper buoyant film of the dye solution was selected where the speed of adsorption was rapid in the earlier stages as compared to the later ones, where it came to a gradual decrease as equilibrium arrived.

2.6. Adsorption Isotherm. The design and mechanism of a biosorption system for removing dyes from wastewater requires finding of most accurate correlation for the equilibrium curve. Thus, the correlation among the adsorbate and adsorbent is performed by studying the distribution of the dyes among the solid-liquid phases at equilibrium. 10, 15, $20,25,30,35$, and $40 \mathrm{mg} / \mathrm{L}$ concentrations of BG dye in a $250 \mathrm{ml}$ stoppered conical flask were selected for isothermal studies along with optimum conditions of temperature, $\mathrm{pH}$, adsorbent dose, contact time, and agitation speed. It determines the characteristics of the adsorbent's surface, its capacity, and mechanism of the underlying process [13]. The isothermal study in this work was conducted by using Langmuir, Freundlich, Temkin, and D-R isotherms.

The most popular isotherm is the Langmuir isotherm. According to this isotherm, there is a finite number of active sites, homogeneously distributed over the adsorbent's surface area and having the same affinity for adsorption of a monolayer, with no interaction among adsorbed molecules. Its linear form is [39]

$$
\frac{1}{q_{e}}=\frac{1}{b q_{\max }} \cdot \frac{1}{C_{\mathrm{e}}}+\frac{1}{q_{\max }}
$$

where $b$ is called the Langmuir constant $(\mathrm{L} / \mathrm{mg}) ; q_{\mathrm{e}}=$ amount of adsorbate adsorbed at equilibrium $(\mathrm{mg} / \mathrm{g})$; $q_{\max }=$ maximum monolayer uptake ability of the adsorbent (mg/g); and $C_{\mathrm{e}}=$ equilibrium impurity absorption in solution $(\mathrm{mg} / \mathrm{L}) . R_{\mathrm{L}}$ is the separation factor, calculated from Langmuir constants, and $C_{\mathrm{o}}=$ the initial concentration of the dye $(\mathrm{mg} / \mathrm{g})$, as shown in the following equation [40]:

$$
R_{\mathrm{L}}=\frac{1}{1+b C_{\mathrm{o}}}
$$

The value of $R_{\mathrm{L}}$ displays the isothermal studies to be unfavorable $\left(R_{\mathrm{L}}>1\right)$, linear $\left(R_{\mathrm{L}}=0\right)$, favorable $\left(0<R_{\mathrm{L}}<1\right)$, or irreversible $\left(R_{\mathrm{L}}<0\right)$. A graph between $1 / q_{\mathrm{e}}$ and $1 / C_{\mathrm{e}}$ displays the desired results.

Another popular model is the Freundlich isotherm. Physisorption (physical adsorption) of adsorbates on the adsorbent layer enhances interactions among adsorbed particles favoring heterogeneous, multilayer adsorption on exterior rough surfaces [41]:

$$
\log q_{e}=\log K_{\mathrm{f}}+\frac{1}{n} \log C_{\mathrm{e}},
$$

where $K_{\mathrm{f}}$ represents the binding constant and $n$ is the adsorption strength. Figures of " $n$ " in the range of 1-10 display a good adsorption procedure [42-44]. This model as compared to multi-ions best describes a larger ionic concentrate, involving single-dye ions, where selectivity along with interferences of the ions prompts for other models. The graph of $\log q_{\mathrm{e}}$ vs. $\log C_{\mathrm{e}}$ shows the results.

The Temkin isotherm model considers reduction of adsorption heat in a linear manner and uniform distribution of binding energies during adsorbent-dye reactions [42, 45].

$$
q_{e}=B \ln C_{\mathrm{e}}+B \ln A,
$$

where $A_{\mathrm{T}}=$ constant related to adsorbate-adsorbent at equilibrium $\left(\mathrm{L} \cdot \mathrm{g}^{-1}\right)$ and $B_{\mathrm{T}}=$ Temkin constant associated to heat of adsorption $\left(\mathrm{J} \cdot \mathrm{mol}^{-1}\right)$

Nature of binding forces based on $B_{\mathrm{T}}$ values imply that values lower than 8 demonstrate a weak physisorption process, while numbers higher than 8 are responsible for a strong chemisorption process among the adsorbate-adsorbent molecules $[46,47]$. Linear plots of $q_{\mathrm{e}}$ against $\ln C_{\mathrm{e}}$ aid in determining of the sorption heats $B_{\mathrm{T}}$ and biosorption potentials $A_{\mathrm{T}}$ values.

The $\mathrm{D}-\mathrm{R}$ isotherm demonstrates the adsorption process considering Gaussian energy distributions onto both homogeneous and heterogeneous surfaces [48, 49] for intermediate concentration ranges. It represents the total free energy along with physical or chemical characteristics of the adsorption process expressed as follows:

$$
\begin{aligned}
\ln q_{e} & =\ln q_{m}-\beta \varepsilon^{2}, \\
\varepsilon & =\mathrm{RT} \ln \left(1+\frac{1}{C_{\mathrm{e}}}\right) .
\end{aligned}
$$

$\mathrm{E}$ is the mean free energy whose values are calculated by considering “ $\beta$ ” $\left(\mathrm{mol}^{2} / \mathrm{J}^{2}\right)$. 


$$
E=\frac{1}{\sqrt{2 \beta}} .
$$

The inference of the adsorption process is based on $E$ values where a value lower than $8 \mathrm{~kJ} / \mathrm{mol}$ represents physisorption, and an intermediate range of 8 to $16 \mathrm{~kJ} / \mathrm{mol}$ shows an ion-exchange reaction and above $16 \mathrm{~kJ} / \mathrm{mol}$ demonstrates a chemisorption one [40]. Linear plots of $\ln q_{e}$ vs $\varepsilon^{2}$ provide the desired results.

\section{Results and Discussion}

3.1. Characterization of Adsorbents. The suitable chemical used for chemical modification was selected by using different chemically modified biowastes for removing BG dye in the batch mode as shown in (Figure 1), and results indicated that tartaric-acid-modified adsorbents had shown best results. It is because BG is basic in nature, so it reacts more with acid-modified biowaste. So, further studies were carried out with tartaric-acid-modified biosorbents.

Both unmodified and modified biowastes were used separately for removing BG dye. The obtained results are as follows [50].

3.2. Chemical Treatment. Pretreatment can be carried out by a variety of methods using acidic (hydrochloric acid, citric acid, tartaric acid, sulfuric acid, and nitric acid), basic (sodium carbonate, sodium hydroxide, and calcium hydroxide), chelating (ethylenediamine and epichlorohydrin), or oxidizing (hydrogen peroxide) agents [51]. Chemical treatment ensures uniformity in ionic distributions, reducing moisture levels that guarantees lower decomposition of the entities. Moreover, acid and basic treatment enhances protonation, ester bonding, and higher micropore proportions, leading to early attainment of equilibrium [27, 52-55]. Tartaric acid was selected as the chemical modifier as it yielded the highest percentages of dye removal as shown in Figure 1.

3.3. Fourier-Transform Infrared (FTIR) Analysis. Surface morphology describes about the material geometry, topology, and surface structure.

The geometry ranges from microscale to the mesoelements and their ordered as well as complexed shapes. The topology describes the connection between micro- and mesoscale elements. The rough surfaces possess complex features upon close inspection, and their characterization gives us deep insights about the material's microstructure along with effective properties [56]. FTIR helps in the molecular composition, structure, and energy-level transitions of unknown surfaces and layers close to it. It is employed when samples are subjected to infrared radiations and bonds between diverse elements absorb light at different frequencies [57]. Group frequencies applied to most compounds having that particular functional group along with skeletal vibrations, unique to specific molecules, are combined to identify the unknown compounds. These are carried out by visual comparison or computerized

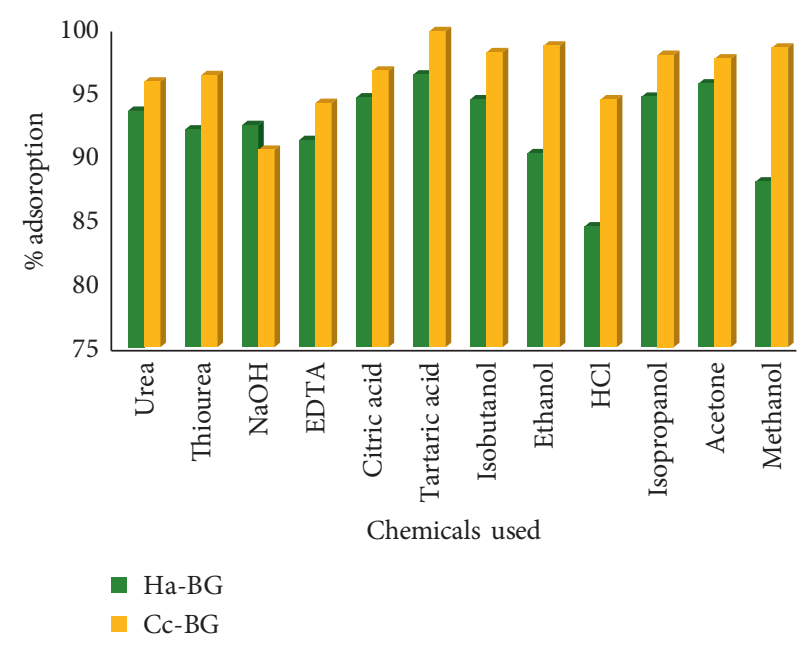

FIGURE 1: Chemical modification of biowaste.

searching, where the adsorption band is in proportion to number times of occurrence of the functional groups within the molecule [58]. The functional groups that are responsible for elucidation of $\mathrm{BG}$ dye from the adsorbent surfaces are determined by it. BG-dye-loaded Ha spectra were studied (Figure 2(a)), where adsorption bands at $3278.2 \mathrm{~cm}^{-1}$ and $3010.8 \mathrm{~cm}^{-1}$ were observed, which represent free $(\mathrm{O}-\mathrm{H})$ and bended $(-\mathrm{NH})$ groups of acidic and aliphatic compounds. Peaks at $2922.2 \mathrm{~cm}^{-1}$ and $2852.3 \mathrm{~cm}^{-1}$ show $(-\mathrm{C}-\mathrm{H})$ stretching vibrations. Bands of $(-\mathrm{OH})$ and $(\mathrm{C}-\mathrm{H})$ confirm the cellulose and lignin structures, while $(-\mathrm{C}=\mathrm{O})$ indicate hemicellulose groups in $\mathrm{Ha}$. $1743.5 \mathrm{~cm}^{-1}$ displays $(-\mathrm{C}=\mathrm{O})$ of aldehydic groups. $1653.1 \mathrm{~cm}^{-1}$ shows $(-\mathrm{C}=\mathrm{O})$ stretch of aromatic amides $\left(\mathrm{RC}(=\mathrm{O}) \mathrm{NR}^{\prime} \mathrm{R}^{\prime \prime}\right)$ and $(\mathrm{C}=\mathrm{C})$ and $(\mathrm{O}-\mathrm{H})$ bending of water/ dye adsorption. Deformation of $(\mathrm{C}-\mathrm{O})$ bonds are evident from $1028 \mathrm{~cm}^{-1}$. These functional groups are responsible for binding electropositive BG dye and COO groups of $\mathrm{Ha}$ by (1) electrostatic attractions among the dye and electronrich functional moieties of the adsorbent, (2) chemical interactions between BG and the surface of adsorbents, and (3) physical forces of attractions (hydrogen bonding and van der Waals interactions) between dye and adsorbents [59]. The IR spectrum of Ha-Ta with BG (Figure 2(b)) showed new peaks of $(-\mathrm{OH})$ at $3737 \mathrm{~cm}^{-1}, 3568.7 \mathrm{~cm}^{-1}$, and $3650 \mathrm{~cm}^{-1}$ when tartaric acid reacted. (-C-H) bonds in methylene groups were reduced at $2850.6 \mathrm{~cm}^{-1}$ and $2918 \mathrm{~cm}^{-1}$, respectively. $1653.3 \mathrm{~cm}^{-1}$ and $1635.8 \mathrm{~cm}^{-1}$ represent $(-\mathrm{C}=\mathrm{O})$ of the carbonyl group. Aromatic ester was seen at $1740.6 \mathrm{~cm}^{-1}$ that indicated the reaction of tartaric acid with the adsorbent. Peaks at $1654 \mathrm{~cm}^{-1}$ and $1647 \mathrm{~cm}^{-1}$ were evident of $(-\mathrm{C}=\mathrm{O})$ stretch of amides, alkenes, and alcohol bending, indicating the electrostatic attractions among the dye and the modified adsorbent. $1559 \mathrm{~cm}^{-1}$ and $1419 \mathrm{~cm}^{-1}$ represented stretching vibrations in aromatic rings [59], while the (C-O) bond deformed at 1029. When Cc reacts with BG (Figure $2(\mathrm{c})$ ), $3737.6 \mathrm{~cm}^{-1}$ and $3568.7 \mathrm{~cm}^{-1}$ broad peaks of $(-\mathrm{OH}) /(-\mathrm{NH})$ groups are seen; also, $2922.0 \mathrm{~cm}^{-1}$ and $2850.0 \mathrm{~cm}^{-1}$ show (-C-H) of alkanes. $1741 \mathrm{~cm}^{-1}$ represents aldehydic $(-\mathrm{C}=\mathrm{O})$ groups, 


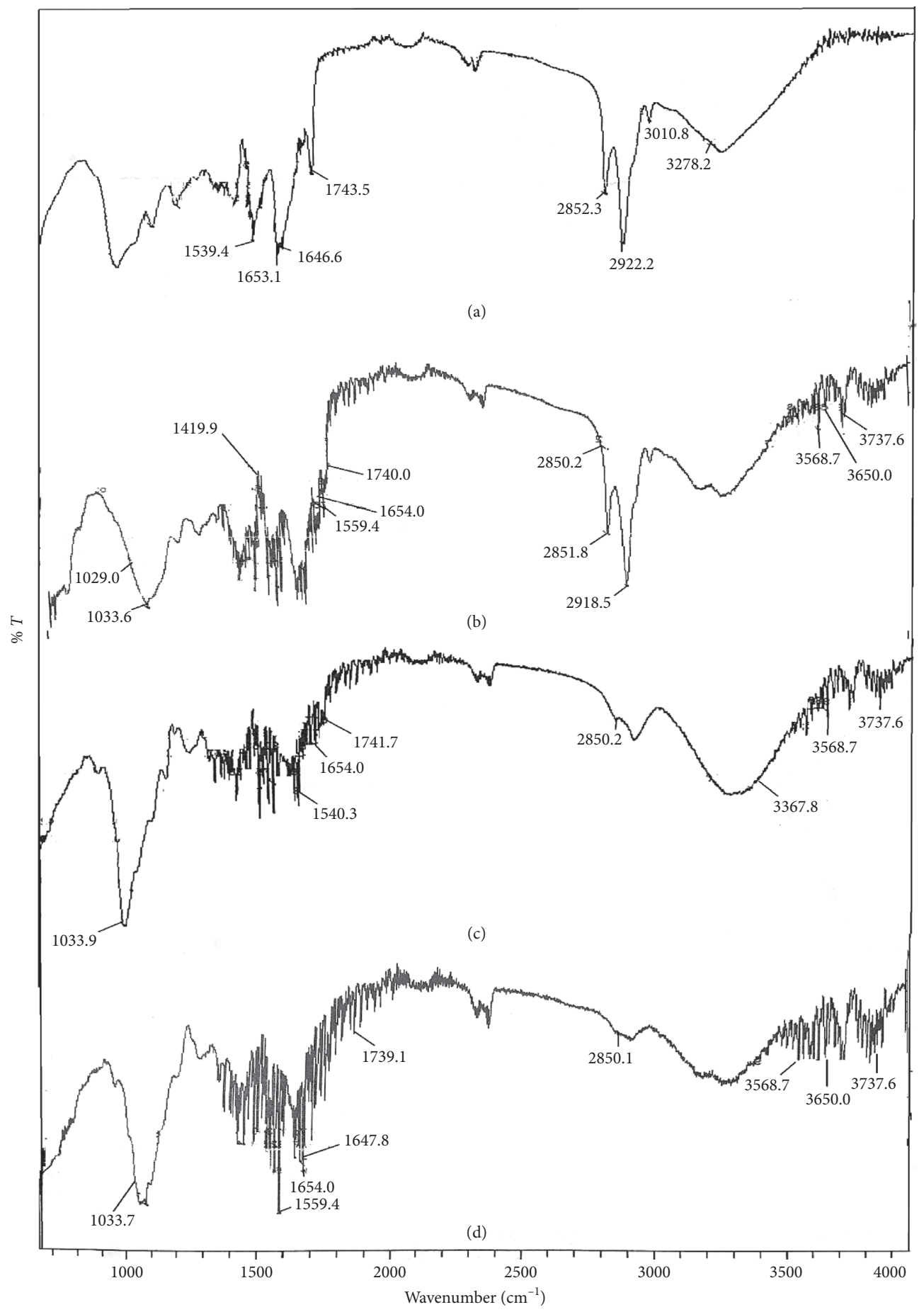

Figure 2: FT-IR spectra of (a) Ha with BG, (b) Ha-Ta with BG, (c) Cc with BG, and (d) Cc-Ta with BG.

while $1654 \mathrm{~cm}^{-1}$ and $1647 \mathrm{~cm}^{-1}$ display amide/alkene/alcohol adsorption. $1540 \mathrm{~cm}^{-1}$ and $1038.8 \mathrm{~cm}^{-1}$ display the aromatic ring and (C-O) stretching. Cc-Ta with $\mathrm{BG}$ spectra (Figure 2(d)) showed reduced peaks at $3737.6 \mathrm{~cm}^{-1}$, $3568.7 \mathrm{~cm}^{-1}$ of $(-\mathrm{OH}) /(-\mathrm{NH})$, and $2850 \mathrm{~cm}^{-1}$ of $(\mathrm{C}-\mathrm{H})$, indicating the reaction of dye with the modified adsorbent. A $1739 \mathrm{~cm}^{-1}$ band was observed along with $1654.3 \mathrm{~cm}^{-1}$, demonstrating the $(-\mathrm{C}=\mathrm{O})$ group. $1033 \mathrm{~cm}^{-1}$ shows $(\mathrm{C}-\mathrm{O})$ stretch. The intensity of the bands shifted or reduced, which indicates the presence of interactions among the adsorbents (raw/modified) and the BG dye [60].

3.4. SEM Analysis. Pretreatment ensures availability of more porous exteriors with larger cavities as the waxes, oils, and some amounts of lignins on the surface are dissolved. The scanning electron micrographs (Figure 3 ) of $\mathrm{Ha}$ and $\mathrm{Cc}$ reveal the complete texture and morphology of the 


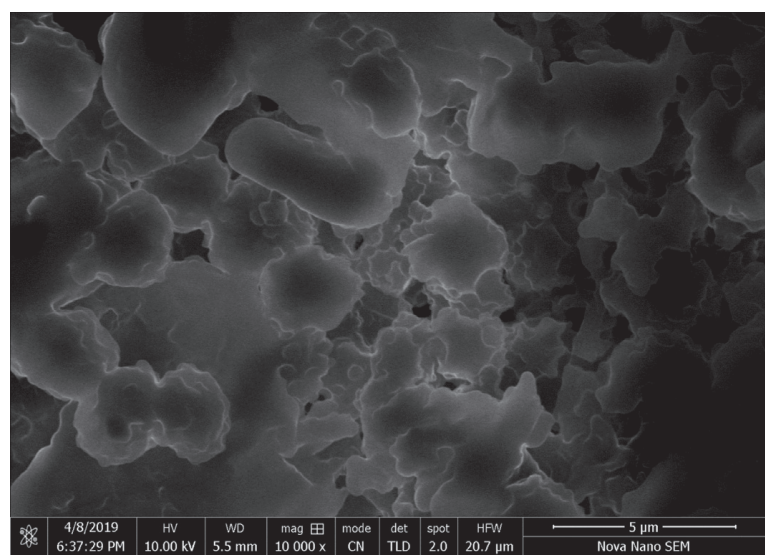

(a)

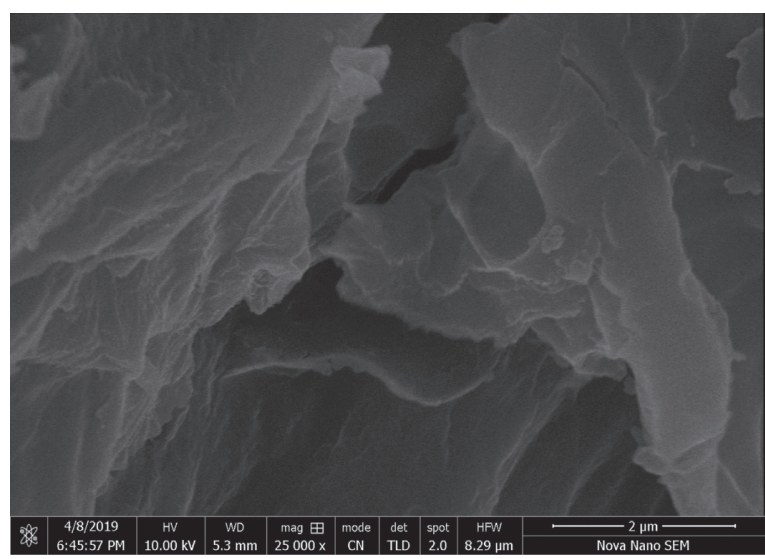

(c)

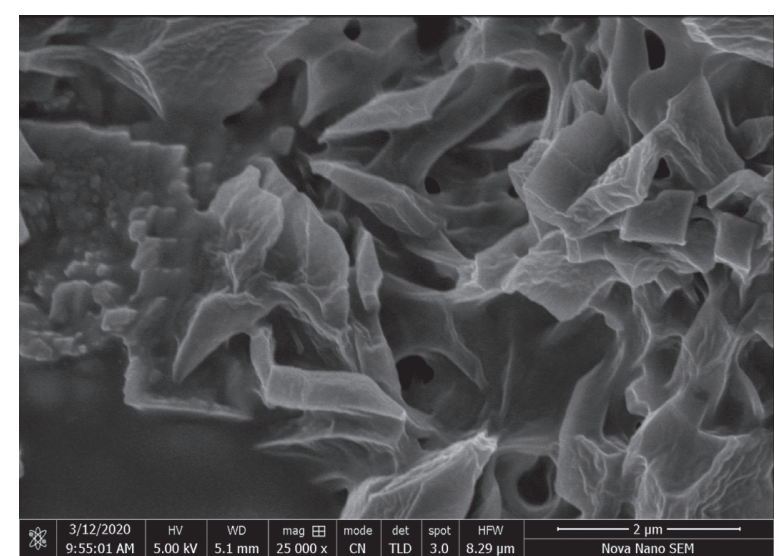

(b)

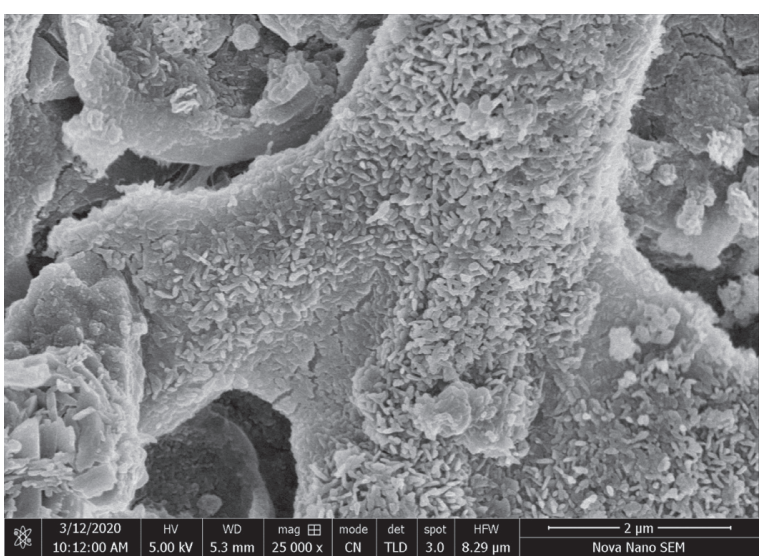

(d)

Figure 3: SEM images of (a) Ha, (b) Ha-Ta, (c) Cc, and (d) Cc-Ta.

adsorbents. From the images, it can be seen that hollow spaces [61] are present among the rigid, spherical edifices [5] of $\mathrm{Ha}$, which facilitated the adsorption of BG dye through physisorption. Acidic treatment resulted in the svelte, etched structures consisting of multifold channels providing more potential sites for BG adsorption [27]. The Cc adsorbent changed from flaky with voids to large agglomerated and bean-like structures attached to the surface when esterification was performed [27].

\subsection{Batch Adsorption Studies}

3.5.1. Effect of Adsorbent Dosage. Adsorbent dose is an important parameter in analyzing the efficiency of the adsorption process. It was calculated by utilizing the dose from $0.2 \mathrm{~g}-2.2 \mathrm{~g}$ with $25 \mathrm{mg} / \mathrm{L}$ dye solution in $250 \mathrm{~mL}$ stoppered Erlenmeyer flasks for both untreated and acid-treated $\mathrm{Ha}$ and Cc adsorbents, as shown in Figure 4(a). For Holarrhena antidysenterica, the adsorption increased up to $2 \mathrm{~g}$ with $96 \%$ dye removal as compared to Citrullus colocynthis, which gave $94 \%$ dye removal at $1.8 \mathrm{~g}$. Tartaric acid modification increased the availability of active surfaces incorporating additional functional moieties of carboxylic and hydroxyl groups leading towards greater dye adsorption than the raw ones, hence leading to $99 \%$ removal at $1.8 \mathrm{~g}$ for modified $\mathrm{Ha}$ and $96 \%$ removal at $1.6 \mathrm{~g}$ for treated Cc. After that, equilibrium rise in concentration leads towards the overlapping of saturated sites and rise in diffusion path lengths [62]. Increase in mass per unit area rises the concentration gradient at higher concentrations resulting in higher BG dye removal $[2,63]$.

3.5.2. Effect of Contact Time. Adsorption improved with rise in contact time until an optimum contact time was achieved [50]. A period of 1 hour with a 5-minute interval was selected utilizing $250 \mathrm{mg} / \mathrm{L}$ dye solution in $250 \mathrm{~mL}$ flasks. Figure 4(b) displays the relative effect of contact time on raw and modified adsorbents. Adsorption rose in early stages as abundance of active surfaces are available, while repelling of adsorbed-unadsorbed moieties resulted in decline at later stages, when molecules penetrate the internal surface [64]. The optimized contact time was $50 \mathrm{~min}$ for both $\mathrm{Ha}$ and $\mathrm{Cc}$, with a percentage of dye removal of $89.35 \%$ for $\mathrm{Ha}$ and of $84.84 \%$ for Cc. After chemical modification, the dye adsorption was seen to be $97 \%$ at 45 minutes for modified $\mathrm{Ha}$ as compared to $93 \%$ at 45 minutes for modified Cc. The driving forces among the liquid and solid phase help in counteracting of the mass transition resistance among the dye molecules $[2,65]$. 


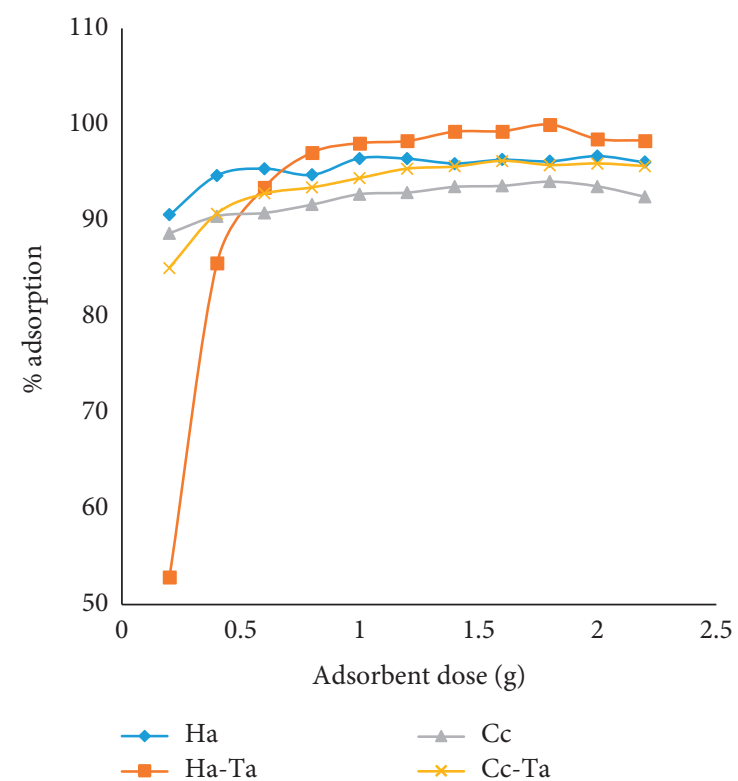

(a)

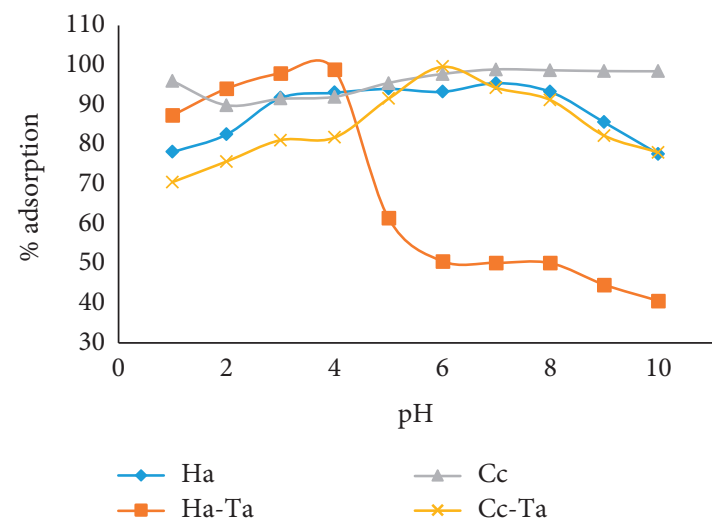

(c)

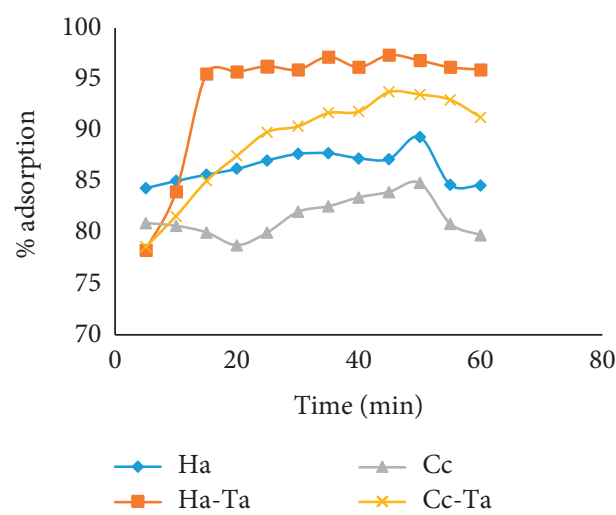

(b)

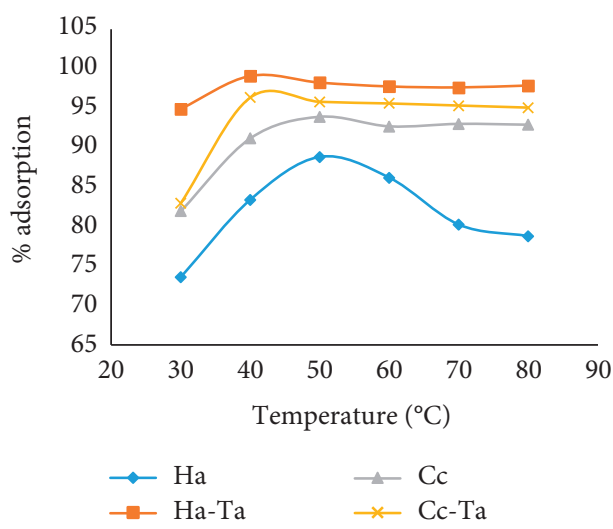

(d)

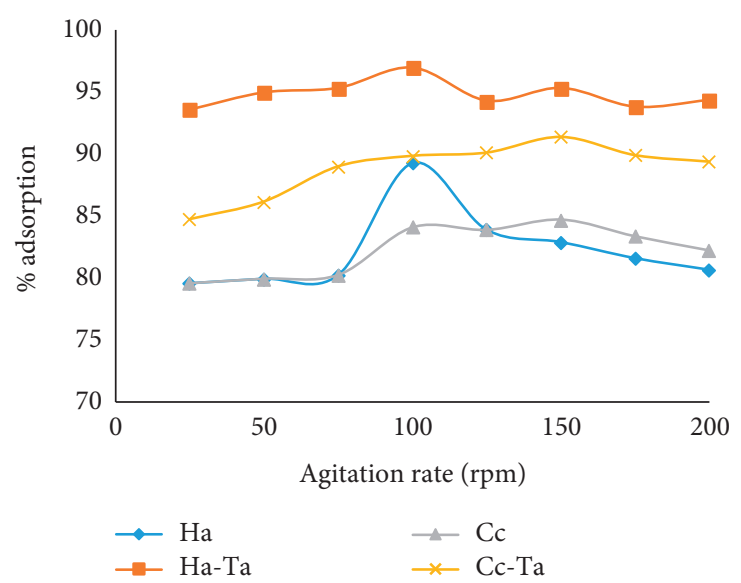

(e)

Figure 4: (a) Adsorbent dose, (b) time effects, (c) pH studies, (d) temperature effects, and (e) agitation rates for BG adsorption.

3.5.3. Effect of $\mathrm{pH}$. Solution $\mathrm{pH}$ controls electrostatic charges and the speciation of adsorbates [66]. The magnitude demonstrated by the charged species of the dyes results in variance of speed of adsorption.
The point of zero-charge $\mathrm{pHpzc}$, where the negative and positive sites are equivalent $[67,68]$, was determined by the electrochemical method [69] as described in our previous studies [27]. Ha gave a pHpzc of 6, and Cc gave 5. Mainly, it 
is observed that, at acidic $\mathrm{pH}$, the adsorbent surface is more positive because of protonation of active sites; hence, decrease in biosorption of basic dyes occur $[2,66]$, whereas at alkaline $\mathrm{pH}$, due to deprotonation, more $-\mathrm{OH}$ ions hinder anionic dyes adsorption, due to the repulsive forces as the adsorbent surface appears to be negatively charged.

Monitored in $\mathrm{pH}(1-10), 25 \mathrm{mg} / \mathrm{L}$ dye solution in $250 \mathrm{~mL}$ stoppered conical flasks, the results (Figure 4(c)) display the best removal (\%) of BG dye for $\mathrm{Ha}$ at $\mathrm{pH} 7(95.44 \%)$ and $\mathrm{Ha}-$ $\mathrm{Ta}(98.83 \%)$ at $\mathrm{pH} 4$ and for $\mathrm{Cc}$ at $\mathrm{pH} 7(98 \%)$ and $\mathrm{Cc}-\mathrm{Ta}$ (99.5\%) at $\mathrm{pH}$ 6. The increased removal of $\mathrm{BG}$ dye in the Ha$\mathrm{Ta}$ and $\mathrm{Cc}-\mathrm{Ta}$ cases is due to the chelation forces, which appear in the case of modified adsorbents. BG, a basic dye existing in the form of positive charged species on the surface of $\mathrm{Ha}$ and $\mathrm{Cc}$, plays a significant role, as the adsorbents are solely dependent upon solution $\mathrm{pH}$ for adsorption.

Excessive $\mathrm{H}^{+}$ions from the protonated forms of carboxyl groups compete with the cationic moieties in the dye for vacant adsorption sites, imparting repulsive forces among the dye and adsorbent surfaces $[67,70]$. Hence, decrease in hydrogen bonding occurs; however, at higher $\mathrm{pH}$, as observed in $\mathrm{Ha}$ and $\mathrm{Cc}$, positive charges are reduced at the adsorbate-adsorbent interface and negative charges of $\mathrm{COO}^{-}$groups of the adsorbent dominate, resulting in enhanced dye removal through electrostatic forces of attraction [9].

3.5.4. Effect of Temperature. Temperature generates the energy required to conquer the mass transfer barrier present among the dye solution and adsorbent potential sites. A range of $30-80^{\circ} \mathrm{C}$ was selected for temperature studies, as shown in Figure $4(\mathrm{~d})$. At $50^{\circ} \mathrm{C}$, a percentage removal of $88.83 \%$ was observed for $\mathrm{Ha}$ and $93 \%$ for Cc. Tartaric acid treatment yielded maximum adsorption of $99 \%$ for modified $\mathrm{Ha}$ and $96 \%$ for treated $\mathrm{Cc}$ at $40^{\circ} \mathrm{C}$. Biosorption increased with an increase in temperature, favoring the increase of entropy that strikes the color moieties against the potential binding surfaces, which leads to an increased speed of the process; also, the inflammation of adsorbent sites increased the active sites of the biological material, resulting in a larger amount of dye removed. An increase in the porosity of pore volumes of adsorbents rises the kinetic energy for better dye removal [2].

3.5.5. Effect of Agitation Rate. Agitation rate determines the distribution of solute particles in the bulk solution and the outer exterior film formation; the $20-200 \mathrm{rpm}$ range was chosen during experimentation. At $100 \mathrm{rpm} 89 \%$, dye removal was demonstrated for Ha which rose up to $96 \%$ for the acid-treated forms while Cc removed $84 \%$ dye at $150 \mathrm{rpm}$, which rose towards $91 \%$ for modified forms (Figure $4(\mathrm{e})$ ). Increase in agitation rate improved BG interactions with the active surfaces of the adsorbent, reducing the resistance of the external boundary sheet and raising mobility. Also, the external mass transfer coefficient increased; thus, better adsorption of the dye molecules was achieved [71]. Increased agitation speed produces higher centripetal force among the dye molecules that imparts repulsion among them, overcoming binding forces, and the mechanism shifts towards desorption [2].

3.6. Adsorption Isotherm. An adsorption isotherm was conducted using Langmuir, Freundlich, Temkin, and D-R isotherms. Results are presented in Table 1 along with graphs in (Figure 5). The values of correlation coefficient $R^{2}$ are in close proximity to the one confirming the Langmuir isotherm model to be in complete agreement for adsorption of BG onto both the adsorbents. $Q_{\max }$ for $\mathrm{Ha}$ and its modified forms were greater, implementing adsorption of BG better than $\mathrm{Cc}$ and its treated forms. Also, it is seen that the biosorption process is monolayer, homogeneous, and followed the chemisorption process, inhibiting any side reactions within molecules [72]. $\mathrm{R}_{\mathrm{L}}$ figures for the adsorption of $\mathrm{BG}$ on raw and modified adsorbents were less than one, showing a favorable biosorption process $[13,73]$. The $b$ values indicate significant affinities of biosorbents for BG dye removal [13]. Freundlich isotherm's results present that $R^{2}$ values were lesser than that of Langmuir, indicating lesser chances for the physiosorption mechanism. Moreover high charge to mass ratio as well as advanced chelation abilities of BG molecules lead towards better binding capacities of the modified forms. Furthermore, lower values of regression coefficients render the experimental fitting towards the Temkin isotherm. For D-R isotherms $R^{2}$ values were seen to be lesser than other isothermals, and $E$ values favored the physisorption process. $Q_{m}$ values of the modified forms were higher than the raw ones.

3.7. Adsorption Kinetics Studies. The outcomes of the kinetic modeling are displayed in Figure 6 and Table 2. From the data obtained, it can clearly be illustrated that the pseudosecond-order equation seems to be the most accepted model for BG adsorption on raw and modified forms of adsorbent as evident from $R^{2}$ depicting the chemisorption process indicating covalent boding through sharing or electron transferring. A larger variance of $P$ values is observed among the experimental and calculated values for the pseudo-firsorder kinetics as compared to the second order, hence rendering it ineffective against the pseudo-second-order, where the difference among $P$ values are far less. Also, a rise in initial sorption rates " $h$ " and decrease in half-lives " $t$ "1/2" were observed from moving from the raw towards the modified forms [52, 74]. In the Elovich model, binding rate " $a$ " increased for the acid treated while $R^{2}$ displayed a lesser fitting.

3.8. Mass Transfer Parameter. Removal of BG dye on raw and modified adsorbents was rapid in the initial stages and slow in the preceding time. This is carried out by either the boundary-layer diffusion mechanism or intraparticle diffusions. The adsorption process involves (a) film diffusion, transfer of adsorbate towards the solid adsorbent, (b) intraparticle/pore diffusion, diffusion takes place from external to internal pores, and (c) formation of complexes 
TABLE 1: Isothermal parameters for BG dye adsorption.

\begin{tabular}{|c|c|c|c|c|}
\hline \multirow{2}{*}{ Isotherm models } & \multicolumn{2}{|c|}{$\mathrm{Ha}$} & \multicolumn{2}{|c|}{$\mathrm{Cc}$} \\
\hline & Unmodified & Tartaric acid treated & Unmodified & Tartaric acid treated \\
\hline \multicolumn{5}{|l|}{ Langmuir } \\
\hline$Q_{m}(\mathrm{mg} / \mathrm{g})$ & 55.12 & 112.3 & 50.50 & 79.36 \\
\hline$R_{\mathrm{L}}(\mathrm{L} / \mathrm{mg})$ & $0.24-0.10$ & $0.30-0.14$ & $0.29-0.13$ & $0.23-0.10$ \\
\hline$b(\mathrm{~L} / \mathrm{g})$ & 0.171 & 0.0784 & 0.081 & 0.109 \\
\hline$R^{2}$ & 0.940 & 0.968 & 0.970 & 0.979 \\
\hline RMSE & 2.450 & 1.988 & 6.284 & 4.847 \\
\hline \multicolumn{5}{|l|}{ Freundlich } \\
\hline$n$ & 1.49 & 1.19 & 0.64 & 0.73 \\
\hline$K_{\mathrm{f}}(\mathrm{mg} / \mathrm{g})$ & 5.92 & 7.79 & 2.91 & 8.86 \\
\hline$R^{2}$ & 0.9344 & 0.9432 & 0.9585 & 0.969 \\
\hline RMSE & 2.697 & 2.509 & 1.740 & 4.849 \\
\hline \multicolumn{5}{|l|}{ Temkin } \\
\hline$B(\mathrm{~J} / \mathrm{mol})$ & 0.131 & 0.205 & 0.063 & 0.066 \\
\hline$A(\mathrm{~L} / \mathrm{g})$ & 1.022 & 1.157 & 0.464 & 1.005 \\
\hline$R^{2}$ & 0.9561 & 0.9636 & 0.9043 & 0.9781 \\
\hline RMSE & 2.897 & 2.621 & 2.577 & 5.228 \\
\hline \multicolumn{5}{|l|}{ D-R } \\
\hline$Q_{\mathrm{m}}(\mathrm{mg} / \mathrm{g})$ & 35.573 & 43.008 & 56.758 & 60.685 \\
\hline$B_{\mathrm{D}}\left(\mathrm{mol}^{2} / \mathrm{kJ}^{2}\right)$ & $1 \times 10^{-6}$ & $9 \times 10^{-7}$ & $2 \times 10^{-6}$ & $7 \times 10^{-7}$ \\
\hline$E_{\mathrm{D}}(\mathrm{kJ} / \mathrm{mol})$ & 0.70 & 0.74 & 0.50 & 0.84 \\
\hline$R^{2}$ & 0.8680 & 0.9079 & 0.9183 & 0.9010 \\
\hline RMSE & 3.009 & 2.824 & 3.991 & 5.740 \\
\hline
\end{tabular}
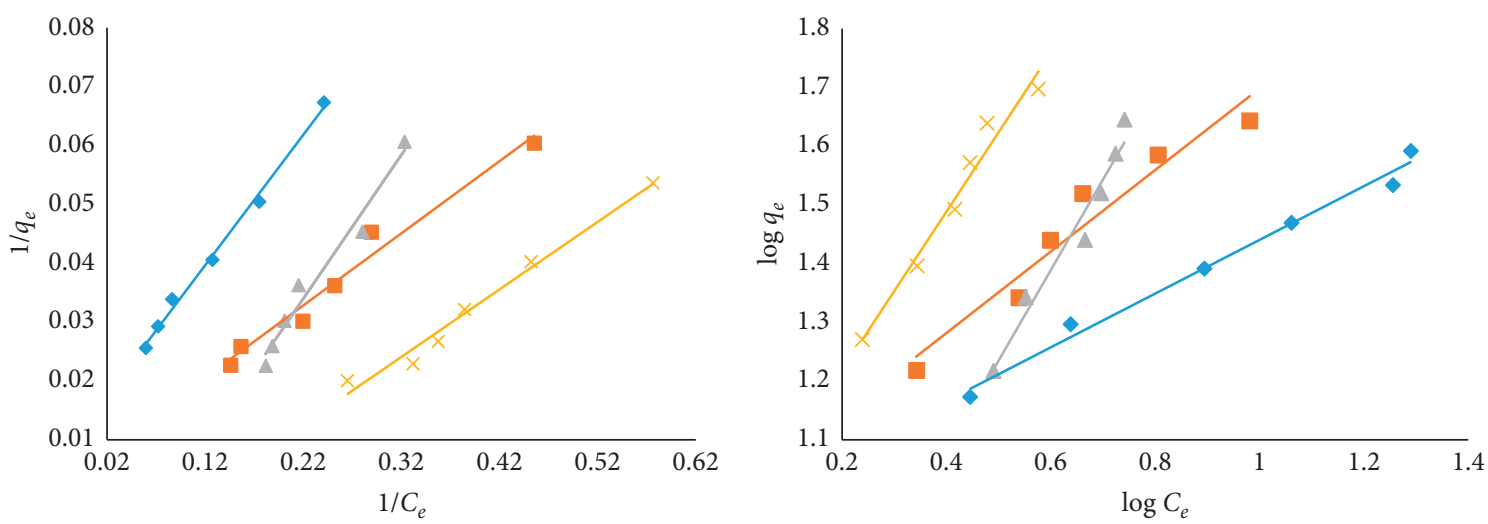

$$
\begin{array}{ll}
\mathrm{Ha} & \triangle \mathrm{Cc} \\
\mathrm{Ha}-\mathrm{Ta} & \times \mathrm{Cc}-\mathrm{Ta}
\end{array}
$$

(a)

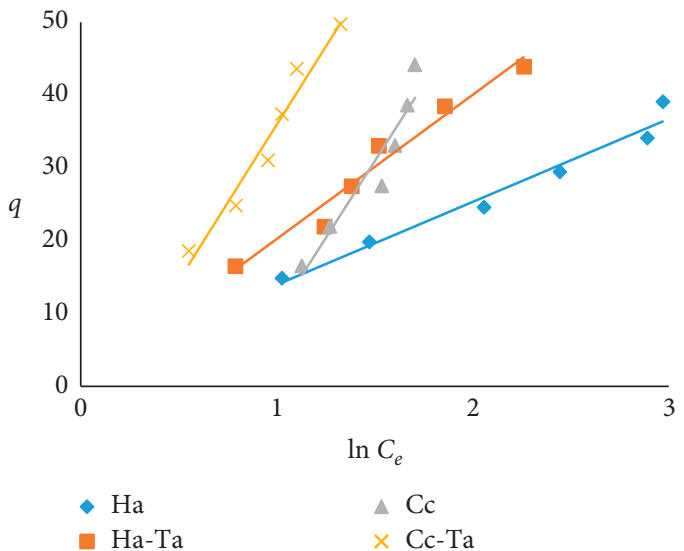

(c)

$$
\text { - Ha }
$$$$
\text { - Ha-Ta }
$$

$\triangle \mathrm{Cc}$

$\times \mathrm{Cc}-\mathrm{Ta}$

(b)

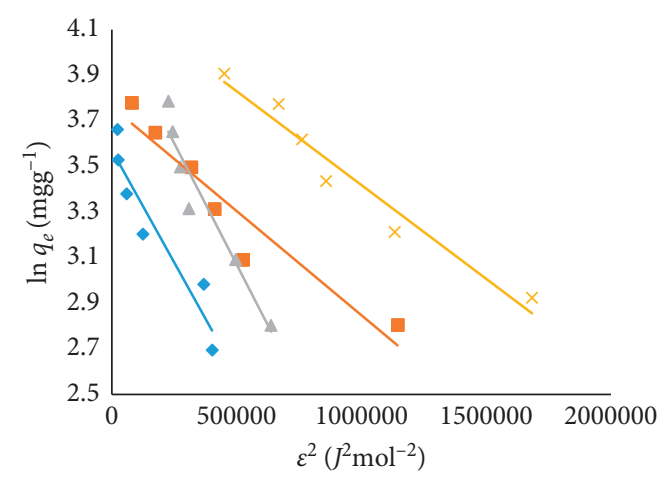

$$
\begin{array}{ll}
-\mathrm{Ha} & \triangle \mathrm{Cc} \\
-\mathrm{Ha}-\mathrm{Ta} & \times \mathrm{Cc}-\mathrm{Ta}
\end{array}
$$

(d)

Figure 5: Comparative representation of (a) Langmuir, (b) Freundlich, (c) Temkin, and (d) D-R isothermal parameters. 

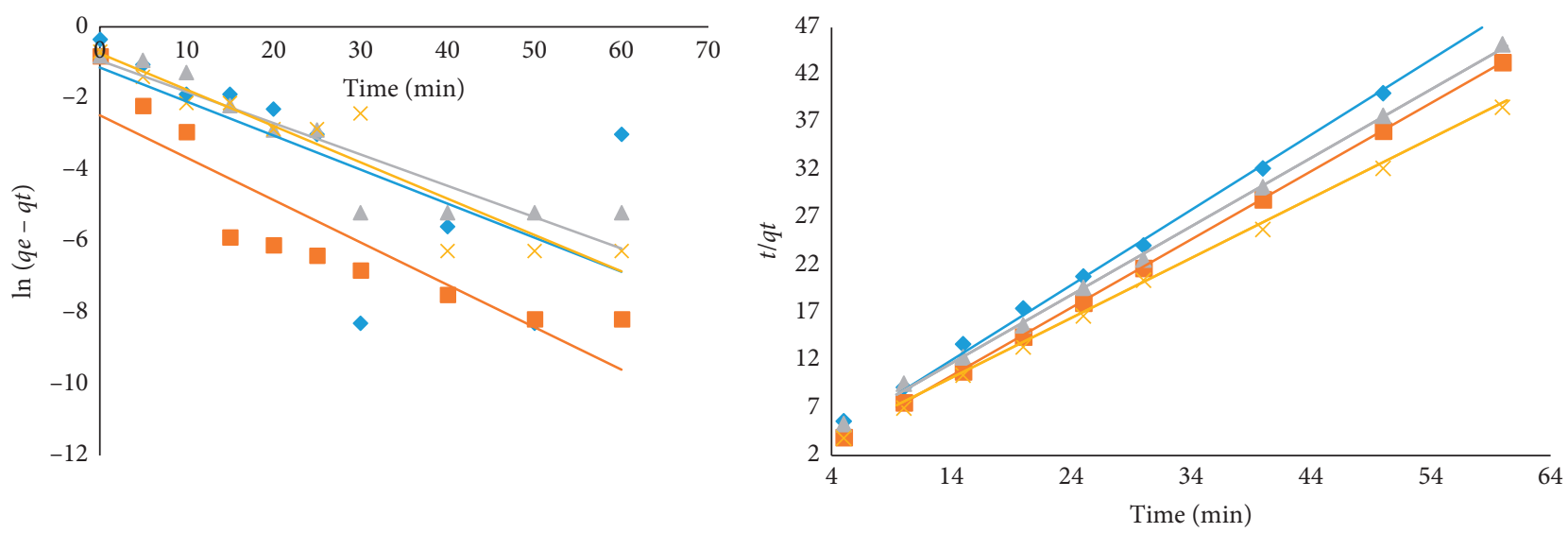
- Ha
- Ha-Ta
$\triangle \mathrm{Cc}$
$\times \mathrm{Cc}-\mathrm{Ta}$

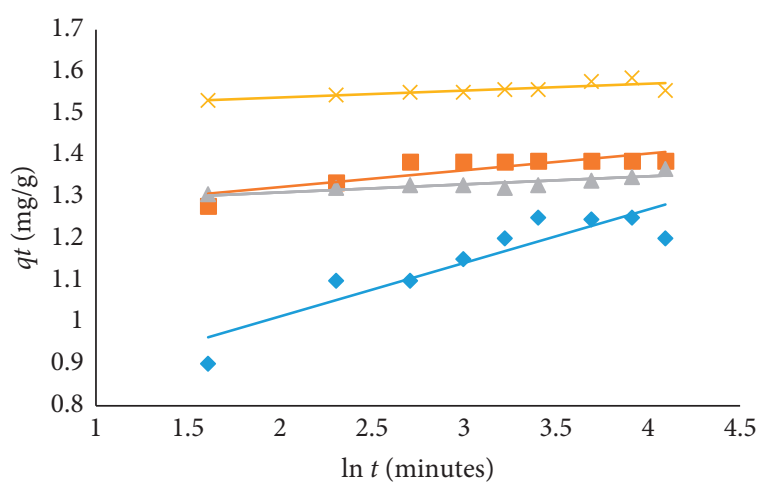

- Ha

- Ha-Ta

$\triangle \mathrm{Cc}$

$\times \mathrm{Cc}-\mathrm{Ta}$

(c)

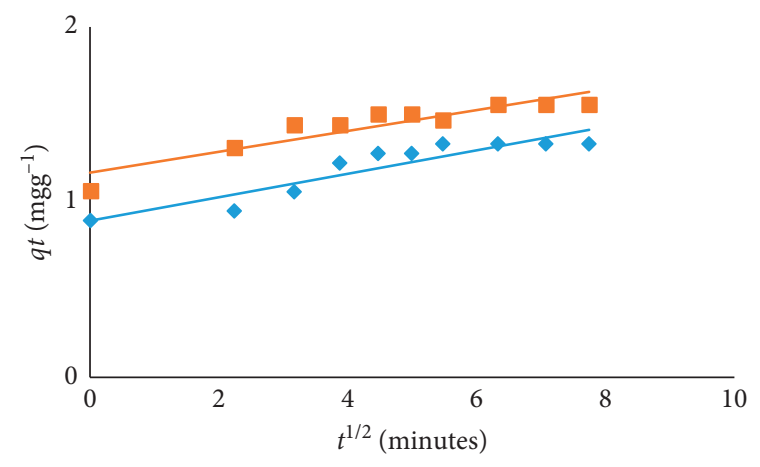

- $\mathrm{Cc}$

- Cc-Ta

(a)

$$
\begin{aligned}
& \text { - Ha } \\
& \text { - Ha-Ta }
\end{aligned}
$$

$\triangle \mathrm{Cc}$

$\times$ Cc-Ta

(b)

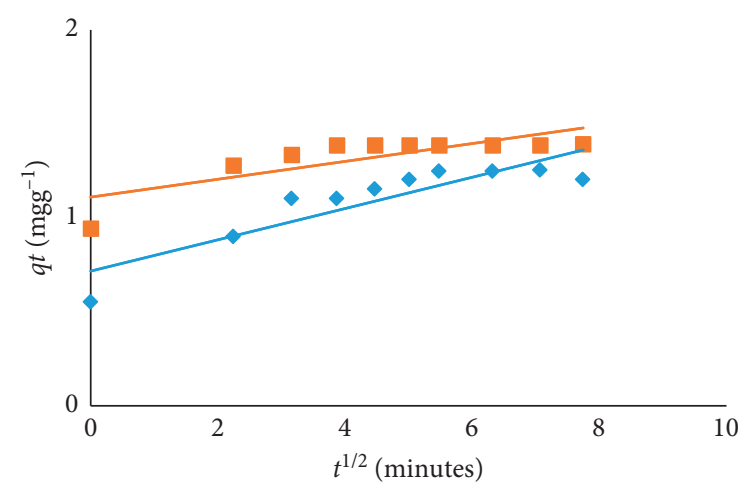

- Ha

- Ha-Ta

(d)

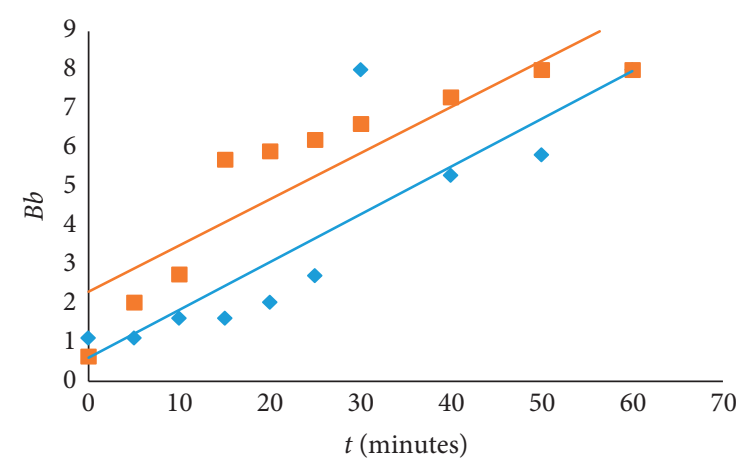

- $\mathrm{Ha}$

- Ha-Ta

(e)

(f)

Figure 6: Continued. 


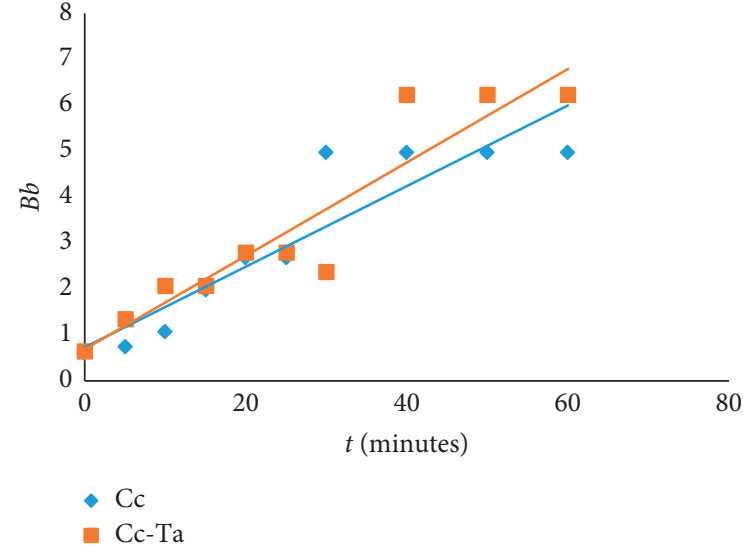

(g)

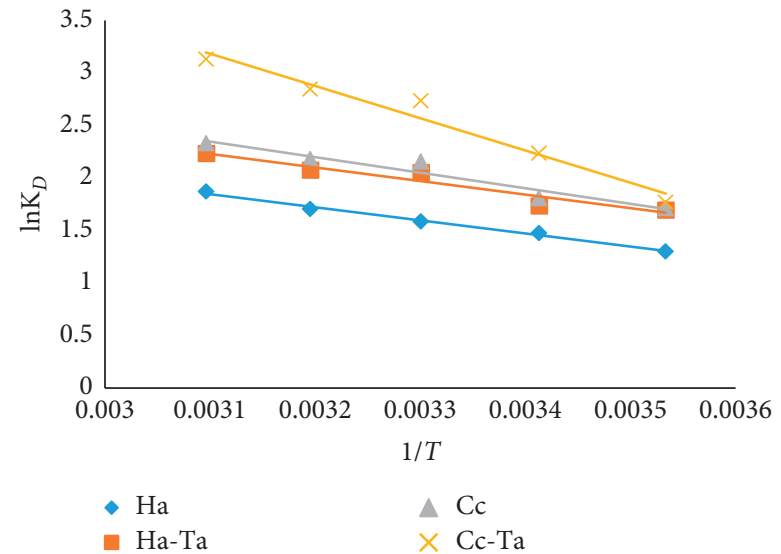

(h)

Figure 6: (a) Pseudo-first-order kinetics, (b) pseudo-second-order kinetics, (c) Elovich plots, (d) Webber-Morris plots for Ha and Ha-Ta, (e)Webber-Morris plots for Cc and Cc-Ta, (f) Boyd's plots for Ha and Ha-Ta, (g) Boyd's plots for Cc and Cc-Ta, and (h) thermodynamic parameters of BG dye.

TABLE 2: Kinetic parameters for BG dye adsorption.

\begin{tabular}{|c|c|c|c|c|}
\hline \multirow{2}{*}{ Kinetic models } & \multicolumn{2}{|c|}{$\mathrm{Ha}$} & \multicolumn{2}{|c|}{$\mathrm{Cc}$} \\
\hline & Unmodified & Tartaric acid treated & Unmodified & Tartaric acid treated \\
\hline \multicolumn{5}{|l|}{ Elovich } \\
\hline $\mathrm{a}(\mathrm{g} / \mathrm{mg} \min )$ & 2.134 & 3.455 & 3.568 & 4.503 \\
\hline$b(\mathrm{~g} / \mathrm{mg})$ & 7.818 & 24.937 & 51.813 & 60.975 \\
\hline$R^{2}$ & 0.8267 & 0.7184 & 0.6633 & 0.7583 \\
\hline RMSE & 0.124 & 0.335 & 0.338 & 0.411 \\
\hline \multicolumn{5}{|l|}{ Pseudo-first-order } \\
\hline$q_{\mathrm{e}}(\exp )(\mathrm{mg} / \mathrm{g})$ & 1.24975 & 1.38667 & 1.33333 & 1.55687 \\
\hline$q_{\mathrm{e}}(\mathrm{mg} / \mathrm{g})$ & 0.07262732 & 0.01333580 & 0.11460406 & 0.18059262 \\
\hline$k_{1}\left(\min ^{-1}\right)$ & 0.2194759 & 0.2735042 & 0.2022034 & 0.2342151 \\
\hline$R^{2}$ & 0.4307 & 0.8048 & 0.8474 & 0.8798 \\
\hline$P(\%)$ & 11.91 & 13.84 & 12.47 & 14.41 \\
\hline RMSE & 0.327 & 0.420 & 0.302 & 0.387 \\
\hline \multicolumn{5}{|l|}{ Pseudo-second-order } \\
\hline $\mathrm{q}^{-1}$ & 0.7991 & 0.7182 & 0.7315 & 0.6308 \\
\hline$k_{2}(\mathrm{~g} /(\mathrm{mg} \cdot \mathrm{min}))$ & 0.7203 & 3.5041 & 0.2832 & 0.4662 \\
\hline$q_{\mathrm{e}}(\mathrm{mg} / \mathrm{g})$ & 1.2514 & 1.3923 & 1.3671 & 1.5852 \\
\hline$t^{1 / 2}$ & 1.109 & 0.205 & 2.582 & 1.353 \\
\hline$h(\mathrm{mg} / \mathrm{g} \cdot \mathrm{min})$ & 0.958 & 6.793 & 0.529 & 1.171 \\
\hline$R^{2}$ & 0.9975 & 0.999 & 0.9981 & 0.9981 \\
\hline$P(\%)$ & 2.48 & 3.83 & 3.08 & 5.39 \\
\hline RMSE & 0.020 & 0.003 & 0.017 & 0.005 \\
\hline \multicolumn{5}{|l|}{ Intraparticle diffusion } \\
\hline$k_{i d}\left(\mathrm{mg} /\left(\mathrm{g} \mathrm{min}^{1 / 2}\right)\right.$ & 0.0473 & 0.0833 & 0.0595 & 0.067 \\
\hline$C\left(\mathrm{mg} \mathrm{g}^{-1}\right)$ & 0.7167 & 1.1109 & 0.8940 & 1.1685 \\
\hline$R^{2}$ & 0.6373 & 0.7928 & 0.8436 & 0.8465 \\
\hline \multicolumn{5}{|l|}{ Film diffusion } \\
\hline$K_{\mathrm{ED}}(1 / \mathrm{min})$ & 0.1228 & 0.1187 & 0.0878 & 0.1017 \\
\hline$R^{2}$ & 0.7467 & 0.8408 & 0.8474 & 0.8798 \\
\hline
\end{tabular}

among the dye and functional moieties in the adsorbent [34]. This model was introduced for the realization of the mechanism [75]. The Webber and Morris equation is as follows:

$$
q_{t}=k_{i d} t^{1 / 2}
$$

where $k_{i d}$ is the coefficient of intraparticle diffusion. Linear plots of qt against $t^{1 / 2}$ intersecting origin favor intraparticle 
diffusion; however, if the data exhibit multilinear plots, then two or more steps are involved. The initial steps are (a) transportation of the dye from the bulk liquid solution to the external boundary surface, (b) diffusion of the liquid film, and (c) particle diffusion within the pores of the adsorbate. Figure 6 displays the dual nature of the model with the curved followed by straight paths, for varying adsorption extents, in the initial and final stages of the experiments. This shows boundary-layer diffusion at initial stages and intraparticle at later stages [76]. The " $C$ " values of thickness of borderline exterior walls were seen to be rising for the modified forms as compared to unmodified ones as implicated by carboxyl and hydroxyl groups on the adsorbent surface leading towards a complex biosorption mechanism [77]. Complete parameters of the intraparticle diffusion model are represented in Table 2.

For the prediction of the actual mechanism involved in the adsorption process, Boyd plots were used to check whether film diffusion or intraparticle diffusion were the rate-determining steps. Fractional achievement of equilibrium with variation in time is known to be the boundarylayer diffusion mechanism. Boyd expression is shown in equation (15), and fractional equilibrium is shown in equation (16):

$$
\ln (1-F)=-\left(K_{f d} t\right)
$$

where $B_{\mathrm{b}}=$ Boyd constant and $F=$ fractional achievement of equilibrium at time $t$, where

$$
F=\frac{q_{t}}{q_{e}}
$$

The intersection of the plots through the origin confirms the Webber-Morris plots, while the boundary layer is the mechanism involved if the intersection is not observed. Graphs between $\mathrm{Bb}$ and $t$ are shown in Figure 6 implying the boundary-layer diffusion mechanism or chemical reaction as the rate-determining approach $[2,66] . K_{f d}$ values are shown in Table 2 clearly indicating the higher $R^{2}$ values than the intraparticle diffusion.

\subsection{Nonlinear Fashion of Equilibrium and Kinetic Modeling.} Nonlinear equilibrium and kinetic modeling are employed for the validation of the equilibrium and kinetic data. Nonlinear forms of Langmuir, Freundlich, Temkin, and Dubinin-Radushkevich [78] are shown in equations (17)-(20), respectively. Also, the rearrangement of kinetic (equations (10)-(12)) revealed the nonlinear forms (equations (21)-(23)).

$$
\begin{aligned}
& q_{t}=q_{e}\left(1-\exp -k_{1} t\right), \\
& q_{t}=\frac{t \cdot k_{2}\left(q_{e}\right)^{2}}{1+t k_{2} \cdot q_{e}}, \\
& q_{t}=\frac{1}{b}(\ln (a \cdot b \cdot t)),
\end{aligned}
$$

$$
\begin{aligned}
& q_{e}=\frac{b \cdot q_{\max } \cdot c_{e}}{1+b \cdot c_{e}}, \\
& q_{e}=K_{f} C_{e}{ }^{1 / n}, \\
& q_{e}=B_{T} \ln \left(K_{T} \cdot C_{e}\right), \\
& q_{e}=q_{m} \exp \left(-\beta \varepsilon^{2}\right) .
\end{aligned}
$$

3.10. Error Calculation. In this study, nonlinear regression error function and RMSE values (equation (24)) were also calculated to check the variation of experimented and calculated values, and the least error gave the most promising equilibrium and kinetic model [79].

$$
\text { RMSE }=\sqrt{\sum \frac{\left(q_{e(\text { cal })}-q_{e(\exp )}\right)^{2}}{N}},
$$

where $q_{e}$ (cal) $\left(\mathrm{mg} \mathrm{g}^{-1}\right)$ is the calculated value and $q_{e}$ (exp) $(\mathrm{mg}$ $\left.\mathrm{g}^{-1}\right)$ is the experimental value, at any instant $t$, and $N$ is data points. The Langmuir model was seemed to be followed by the raw and modified forms except for the BG with CC, which confided with the Freundlich model. The pseudosecond-order model was found to be most appropriate by displaying the highest regression and least error values (Table 2).

3.11. Thermodynamic Studies. Thermodynamic studies undergoing within the biosorption process were evaluated by equations (25)-(27), and the obtained results are presented in Table 3 along with graphs in Figure 6 [40].

$$
\begin{aligned}
\ln K_{\mathrm{d}} & =\frac{-\Delta H^{\circ}}{\mathrm{RT}}+\frac{\Delta S^{\circ}}{R}, \\
\Delta G^{\circ} & =-\mathrm{RT} \ln K_{\mathrm{d}}, \\
K_{\mathrm{d}} & =\frac{Q_{e}}{C_{\mathrm{e}}},
\end{aligned}
$$

where $K_{\mathrm{d}}$ is the equilibrium constant, $q_{e}(\mathrm{mg} / \mathrm{g})$ is the amount of dye adsorbed, and $C_{\mathrm{e}}(\mathrm{mg} / \mathrm{L})$ is the concentration of the solution at equilibrium, respectively. $\left(\Delta G^{\circ}\right)$ represents Gibbs free energy, $\Delta H$ and $\Delta S$ are the heat and entropy changes accompanying the adsorption process, $R$ is the universal gas constant $(8.3143 \mathrm{~J} / \mathrm{mol} / \mathrm{K})$, and $T$ is the temperature in $(\mathrm{K})$. Negative $\left(\Delta G^{0}\right)$ values implicit a favorable and spontaneous process; also, values of $K_{\mathrm{d}}$ increased with rise in temperatures indicating favorable adsorption [80]. Negative values of $\left(\Delta H^{0}\right)$ display the exothermic nature [66], and $\left(\Delta S^{0}\right)$ positive values illustrate the elevation of disorderness of the adsorbent-adsorbate interphase within the adsorption process [2]. The Arrhenius equation determines the activation energy: 
TABLE 3: Thermodynamic parameters for BG dye adsorption.

\begin{tabular}{|c|c|c|c|c|c|c|}
\hline Adsorbents & $T(\mathrm{~K})$ & $\Delta G^{0}\left(\mathrm{~kJ} \mathrm{~mol}^{-1}\right)$ & $K_{\mathrm{D}}$ & $\Delta H^{0}\left(\mathrm{~kJ} \mathrm{~mol}{ }^{-1}\right)$ & $\Delta S^{0}\left(\mathrm{~J} \cdot \mathrm{mol}^{-1} \mathrm{~K}^{-1}\right)$ & $\mathrm{Ea}\left(\mathrm{kJ} \cdot \mathrm{mol}^{-1}\right)$ \\
\hline Ha unmodified & $\begin{array}{l}283 \\
293 \\
303 \\
313 \\
323 \\
\end{array}$ & $\begin{array}{l}-3.064 \\
-3.595 \\
-3.988 \\
-4.432 \\
-4.868 \\
\end{array}$ & $\begin{array}{l}3.677 \\
4.373 \\
4.869 \\
5.489 \\
6.492 \\
\end{array}$ & -23.86 & 109.3035 & 10.36 \\
\hline Tartaric acid modified & $\begin{array}{l}283 \\
293 \\
303 \\
313 \\
323 \\
\end{array}$ & $\begin{array}{l}-3.997 \\
-4.241 \\
-5.168 \\
-5.409 \\
-6.006 \\
\end{array}$ & $\begin{array}{l}5.467 \\
5.702 \\
7.777 \\
7.992 \\
9.356 \\
\end{array}$ & -24.72 & 119.3274 & 10.73 \\
\hline Cc unmodified & $\begin{array}{l}283 \\
293 \\
303 \\
313 \\
323 \\
\end{array}$ & $\begin{array}{l}-4.027 \\
-4.412 \\
-5.436 \\
-5.677 \\
-6.266 \\
\end{array}$ & $\begin{array}{c}5.536 \\
6.116 \\
8.651 \\
8.858 \\
10.311 \\
\end{array}$ & -28.35 & 132.8132 & 12.31 \\
\hline Tartaric acid modified & $\begin{array}{l}283 \\
293 \\
303 \\
313 \\
323\end{array}$ & $\begin{array}{l}-4.168 \\
-5.448 \\
-6.900 \\
-7.413 \\
-8.416\end{array}$ & $\begin{array}{c}5.877 \\
9.356 \\
15.465 \\
17.260 \\
22.959\end{array}$ & -58.80 & 243.2349 & 25.53 \\
\hline
\end{tabular}

$$
\ln k=\ln A-\frac{\mathrm{Ea}}{\mathrm{RT}}
$$

where $A$ is the frequency factor, $R$ is the gas constant $\left(8.314 \mathrm{~J} \cdot \mathrm{mol}^{-1} \cdot \mathrm{K}^{-1}\right), k(h-1)$ is the constant rate, and $T$ is the absolute temperature $(\mathrm{K})$. The observed values indicate the reaction to be a physisorption.

3.12. Adsorption Mechanism. The surface of the adsorbent, as evident from the FT-IR analysis, possesses cellulose, lignin, and hemicellulose constituents (Figures 2(a)-2(d)) that contain carboxyl and hydroxyl functional moieties. BG dye and $\mathrm{Ha} / \mathrm{Cc}$ adsorbents are both solvated in water and require rupture of hydration shells for the dye to be adsorbed, hence forming both outer- (nonspecific) and inner-sphere (specific) complexation with the adsorbent. The IR spectrum confirms the whole molecule within the interlamellar space of the adsorbent, also evident in aggregated structures in SEM images. Chemical modification increases the surface porosity and reduces cellulose crystallinity during the esterification reaction. The reaction further exposes inter- and intramolecular hydrogen bonding within the cellulose towards the dye which incorporates within the aggregated cavities during dye adsorption. Outersphere complexes occurs at the organic surface of the adsorbents where the amino group of cationic BG forms electrostatic attractions with the COO groups of the adsorbents. Free lone pairs on nitrogen atom also form hydrogen bonding with OHgroups on the adsorbent. Chemical interactions such as $\pi-\pi$ interactions among the aromatic part of the dye and the oxygen plane of the adsorbent lead towards the inner-sphere complexation. Moreover, $\mathrm{sp}^{3}$ oxygen-containing functional groups pose structural defects on the adsorbent surface [81-83] that facilitate further penetration of the dye towards the micro- and macroporous sites. Hence, boundary-layer diffusion along with intraparticle diffusion occurs into the inner cellulosic layers of the biosorbent. Film distribution is the rate-controlling step as indicated from the kinetic studies. The complete mechanism is displayed in Figure 7 [81]. Similar results are shown in $[2,81]$.

3.13. Comparison of the Adsorption Capacity of Adsorbents with the Literature. A comparison of maximum adsorption capacity of both the adsorbents, in raw and acid-treated forms, is carried out with other alternative bioadsorbents and represented in Table 4. The qmax calculated for $\mathrm{Ha}, \mathrm{Cc}$, $\mathrm{Ha}-\mathrm{Ta}$, and $\mathrm{Cc}-\mathrm{Ta}$ was found to be 55.12, 112.3, 50.5, and $79.36 \mathrm{mg} / \mathrm{g}$, respectively. Hence, the adsorbents yield higher adsorption capacities than most of other adsorbents and can be used for the effective removal of BG dye from wastewaters.

From the literature study, it is seen that any other researcher has not reported removal of BG dye from the abovementioned adsorbents. It is the first research where tartaric-acid-treated $\mathrm{Ha}$ and $\mathrm{Cc}$ adsorbents are used in batch modes for the removal of BG dye, hence establishing the novelty of this work.

3.14. Regeneration Study. Regeneration studies were carried out in three consecutive cycles, and the third cycle still poses $87 \%$ of dye adsorption of BG-Ha. Cc gave $87 \%$, while the modified forms gave $88 \%$ for $\mathrm{Ha}-\mathrm{Ta}$ and $89 \%$ for Cc-Ta. Future research is needed to carry out an adsorption procedure employing these adsorbents for metal sequestration, activated carbon preparation, microwave solid degradation, and removal of other organic pollutants. 


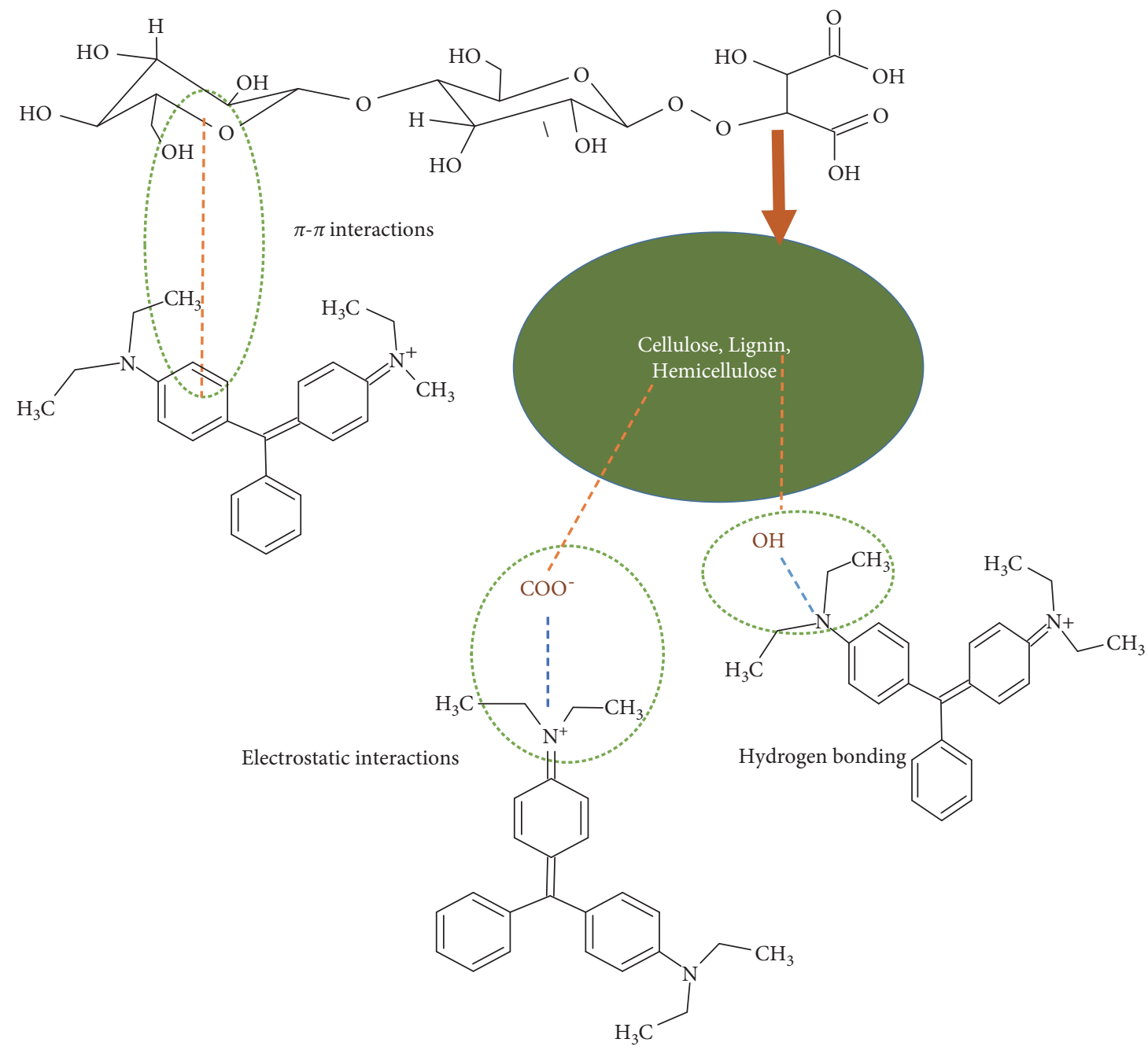

Figure 7: Proposed mechanism for BG dye adsorption.

TABLE 4: Comparison between present and previous adsorbents for BG adsorption.

\begin{tabular}{lcc}
\hline Biosorbents & Qm $\left(\mathrm{mg} \mathrm{g}^{-1}\right)$ & Reference \\
\hline Acorn & 2.11 & {$[84]$} \\
NaOH-treated sawdust & 55.86 & {$[85]$} \\
Pinus roxburghii & 71.42 & {$[3]$} \\
Saklikent & 1.18 & {$[86]$} \\
Red clay & 125 & {$[87]$} \\
Bambusa tulda & 41.67 & {$[87]$} \\
Psidium guajava & 1.173 & {$[88]$} \\
Solanum tuberosum & 1.075 & {$[88]$} \\
Citric acid & 227 & {$[89]$} \\
H. antidysenterica & 55.12 & Present work \\
H. antidysenterica tartaric acid modified & 112.3 & Present work \\
C. colocynthis & 50.5 & Present work \\
C. colocynthis tartaric acid modified & 79.36 & Present work \\
\hline
\end{tabular}




\section{Conclusions}

The study carried out demonstrates that both $H$. antidysenterica and C. colocynthis are inexpensive, environmental-friendly biowaste for the efficient adsorption of dyes from waste waters. The biowastes were treated with tartaric acid, which incorporated the positively charged moieties increasing the dye-removal ability. The characterization techniques demonstrated the presence of $-\mathrm{COOH}$ and $-\mathrm{OH}$ groups that aid in BG dye adsorption by electrostatic attractions, hydrogen bonding, and $\pi-\pi$ interactions. The mechanism is evident of transforming of particles towards the exterior of the surface, followed by shifting of ions within the solution from the exterior surface towards the interior. The adsorption takes place at surfaces with assistance of carboxyl, hydroxyl, and amino groups. At the last stage, the boundary layer and Webber-Morris plots are prevalent into the interior space. Film diffusion along with intraparticle diffusion is the rate-determining step. Isothermal studies, such as Langmuir, Freundlich, Temkin, and $\mathrm{D}-\mathrm{R}$ models, were checked, and the Langmuir model succeeded with the maximum monolayer adsorption capacities for BG dye removal of $112.50 \mathrm{mg} / \mathrm{g}$ for Ha-Ta and $79.36 \mathrm{mg} /$ $\mathrm{g}$ for Cc-Ta. Thermodynamic analysis proved that the adsorption process is exothermic and spontaneous accompanied by increasing entropy. Both raw and modified adsorbents followed the pseudo-second-order kinetic model as evident from kinetic studies.

\section{Abbreviations}

BG: Brilliant green

Ha: Holarrhena antidysenterica

Cc: Citrullus colocynthis

Ha-Ta: H. antidysenterica-tartaric acid modified

Cc-Ta: C. colocynthis-tartaric acid modified

\section{Data Availability}

All related data are mentioned in the manuscript with references.

\section{Conflicts of Interest}

The authors declare that they have no conflicts of interest that can influence the work reported in this paper.

\section{Acknowledgments}

The authors express gratitude to the University of the Punjab, Lahore, Pakistan, for financial support.

\section{References}

[1] U. J. Etim, S. A. Umoren, and U. M. Eduok, "Coconut coir dust as a low cost adsorbent for the removal of cationic dye from aqueous solution," Journal of Saudi Chemical Society, vol. 20, pp. S67-S76, 2016.

[2] K. S. Baidya and U. Kumar, "Adsorption of brilliant green dye from aqueous solution onto chemically modified areca nut husk," South African Journal of Chemical Engineering, vol. 35, pp. 33-43, 2021.

[3] R. Rehman, S. J. Muhammad, and M. Arshad, "Brilliant green and acid orange 74 dyes removal from water by Pinus roxburghii leaves in naturally benign way: an application of green chemistry," Journal of Chemistry, vol. 2019, Article ID 3573704, , 2019.

[4] L. A. Shah, T. Malik, M. Siddiq, A. Haleem, M. Sayed, and A. Naeem, " $\mathrm{TiO}_{2}$ nanotubes doped poly(vinylidene fluoride) polymer membranes (PVDF/TNT) for efficient photocatalytic degradation of brilliant green dye," Journal of Environmental Chemical Engineering, vol. 7, no. 5, p. 103291, 2019.

[5] M. A. Taleb, R. Kumar, A. A. Al-Rashdi, M. K. Seliem, and M. Barakat, "Fabrication of $\mathrm{SiO}_{2} / \mathrm{CuFe}_{2} \mathrm{O}_{4} /$ polyaniline composite: a highly efficient adsorbent for heavy metals removal from aquatic environment," Arabian Journal of Chemistry, vol. 13, no. 10, pp. 7533-7543, 2020.

[6] C. R. Marcelo, G. A. Puiatti, M. A. Nascimento, A. F. Oliveira, and R. P. Lopes, "Degradation of the reactive blue 4 dye in aqueous solution using zero-valent copper nanoparticles," Journal of Nanomaterials, vol. 2018, Article ID 4642038, , 2018.

[7] A. E. Burakov, E. V. Galunin, I. V. Burakova et al., "Adsorption of heavy metals on conventional and nanostructured materials for wastewater treatment purposes: a review," Ecotoxicology and Environmental Safety, vol. 148, pp. 702-712, 2018.

[8] I. Loulidi, F. Boukhlifi, M. Ouchabi et al., "Adsorption of crystal violet onto an agricultural waste residue: kinetics, isotherm, thermodynamics, and mechanism of adsorption," The Scientific World Journal, vol. 2020, Article ID 5873521, 2020.

[9] R. Mansour, A. El Shahawy, A. Attia, and M. S. Beheary, "Brilliant green dye biosorption using activated carbon derived from guava tree wood," International Journal of Chemical Engineering, vol. 2020, Article ID 8053828, 2020.

[10] D. Caparkaya and L. Cavas, "Biosorption of methylene blue by a brown alga cystoseira barbatula kützing," Acta Chimica Slovenica, vol. 55, no. 3, 2008.

[11] K. Jirasripongpun, R. Nasanit, J. Niruntasook, and B. Chotikasatian, Decolorization and Degradation of CI Reactive Red 195 by Enterobacter Sp, pp. 6-11, Science \& Technology Asia, Pathum Thani, Thailand, 2007.

[12] B. K. Nandi, A. Goswami, and M. K. Purkait, "Adsorption characteristics of brilliant green dye on kaolin," Journal of Hazardous Materials, vol. 161, no. 1, pp. 387-395, 2009.

[13] R. Fiaz, M. Hafeez, and R. Mahmood, "Removal of brilliant green (BG) from aqueous solution by using low cost biomass Salix alba leaves (SAL): thermodynamic and kinetic studies," Journal of Water Reuse and Desalination, vol. 10, no. 1, pp. 70-81, 2020.

[14] A. S. Keshtiban, S. Seyedahmadian, B. Habibi, and K. Farhadi, "An electrospun zein/graphene oxide nanofibrous composite: typical application as a new biopolymeric adsorbent in removal of methylene blue and malachite green dyes from aqueous media," Progress in Color, Colorants and Coatings Journal, vol. 14, no. 1, pp. 55-65, 2021.

[15] G. S. Sree, S. M. Botsa, B. J. M. Reddy, and K. V. B. Ranjitha, "Enhanced UV-Visible triggered photocatalytic degradation of Brilliant green by Reduced Graphene Oxide based $\mathrm{NiO}$ and $\mathrm{CuO}$ ternary nanocomposite and their antimicrobial activity," Arabian Journal of Chemistry, vol. 13, no. 4, 2020.

[16] K. Aqeel, H. A. Mubarak, J. Amoako-Attah et al., "Electrochemical removal of brilliant green dye from wastewater," IOP 
Conference Series: Materials Science and Engineering, IOP Publishing, Bristol, UK, 2020.

[17] C. Qi, H. Chen, C. Xu et al., "Synthesis and application of magnetic materials-barium ferrite nanomaterial as an effective microwave catalyst for degradation of brilliant green," Chemosphere, vol. 260, p. 127681, 2020.

[18] M. G. da Rocha, S. Nakagaki, G. M. Ucoski, F. Wypych, and G. Sippel Machado, "Comparison between catalytic activities of two zinc layered hydroxide salts in brilliant green organic dye bleaching," Journal of Colloid and Interface Science, vol. 541, pp. 425-433, 2019.

[19] J. Li, Y. Li, Z. Xiong, G. Yao, and B. Lai, “The electrochemical advanced oxidation processes coupling of oxidants for organic pollutants degradation: a mini-review," Chinese Chemical Letters, vol. 30, no. 12, pp. 2139-2146, 2019.

[20] F. Rehman, M. Sayed, J. A. Khan, N. S. Shah, H. M. Khan, and D. D. Dionysiou, "Oxidative removal of brilliant green by UV/ $\mathrm{S}_{2} \mathrm{O}_{8}{ }^{2-}$, $\mathrm{UV} / \mathrm{HSO}^{5-}$ and $\mathrm{UV} / \mathrm{H}_{2} \mathrm{O}_{2}$ processes in aqueous media: a comparative study," Journal of Hazardous Materials, vol. 357, pp. 506-514, 2018.

[21] F. Soltani-Nezhad, A. Saljooqi, A. Mostafavi, and T. Shamspur, "Synthesis of $\mathrm{Fe}_{3} \mathrm{O}_{4} / \mathrm{CdS}-\mathrm{ZnS}$ nanostructure and its application for photocatalytic degradation of chlorpyrifos pesticide and brilliant green dye from aqueous solutions," Ecotoxicology and Environmental Safety, vol. 189, Article ID 109886, 2020.

[22] S. Joshi, V. K. Garg, N. Kataria, and K. Kadirvelu, "Applications of $\mathrm{Fe}_{3} \mathrm{O}_{4} @ \mathrm{AC}$ nanoparticles for dye removal from simulated wastewater," Chemosphere, vol. 236, Article ID 124280, 2019.

[23] B. S. Kaith, J. Dhiman, and J. Kaur Bhatia, "Preparation and application of grafted Holarrhena antidycentrica fiber as cation exchanger for adsorption of dye from aqueous solution," Journal of Environmental Chemical Engineering, vol. 3, no. 2, pp. 1038-1046, 2015.

[24] S. Sinha, A. Sharma, P. H. Reddy, B. Rathi, N. V. S. R. K. Prasad, and A. Vashishtha, "Evaluation of phytochemical and pharmacological aspects of Holarrhena antidysenterica (Wall.): a comprehensive review," Journal of Pharmacy Research, vol. 6, no. 4, pp. 488-492, 2013.

[25] M. R. R. Kahkha, M. Kaykhaii, and G. Ebrahimzadeh, "Optimization of affective parameter on cadmium removal from an aqueous solution by Citrullus colocynthis powdered fruits by response surface," Health Scope, vol. 4, no. 1, 2015.

[26] A. E. Al-Snafi, "Chemical constituents and pharmacological effects of Citrullus colocynthis-A review," IOSR Journal of Pharmacy, vol. 6, no. 3, pp. 57-67, 2016.

[27] S. Basharat, R. Rehman, T. Mahmud, S. Basharat, and L. Mitu, "Tartaric acid-modified Holarrhena antidysenterica and Citrullus colocynthis biowaste for efficient eradication of crystal violet dye from water," Journal of Chemistry, vol. 2020, Article ID 8862167, , 2020.

[28] R. Rehman, T. Mahmud, and J. Anwar, "Isothermal modeling of batch biosorption of brilliant green dye from water by chemically modified eugenia," Journal of the Chemical Society of Pakistan, vol. 34, no. 1, p. 136, 2012.

[29] Y. İ. Coşkun, N. Aksuner, and J. Yanik, "Sandpaper wastes as adsorbent for the removal of brilliant green and malachite green dye," Acta Chimica Slovenica, vol. 66, no. 2, pp. 402413, 2019.

[30] A. A. Alqadami, M. Naushad, M. A. Abdalla et al., "Efficient removal of toxic metal ions from wastewater using a recyclable nanocomposite: a study of adsorption parameters and interaction mechanism," Journal of Cleaner Production, vol. 156, pp. 426-436, 2017.

[31] S. Chowdhury and P. Saha, "Sea shell powder as a new adsorbent to remove basic green 4 (malachite green) from aqueous solutions: equilibrium, kinetic and thermodynamic studies," Chemical Engineering Journal, vol. 164, no. 1, pp. 168-177, 2010.

[32] Y. S. Ho and G. McKay, "Sorption of dye from aqueous solution by peat," Chemical Engineering Journal, vol. 70, no. 2, pp. 115-124, 1998.

[33] S. Lagergren, "Zur theorie der sogenannten adsorption geloster stoffe," Kungliga Svenska Vetenskapsakademiens, vol. 24, pp. 1-39, 1898.

[34] K. L. Tan and B. H. Hameed, "Insight into the adsorption kinetics models for the removal of contaminants from aqueous solutions," Journal of the Taiwan Institute of Chemical Engineers, vol. 74, pp. 25-48, 2017.

[35] W. Zhu, J. Liu, and M. Li, "Fundamental studies of novel zwitterionic hybrid membranes: kinetic model and mechanism insights into strontium removal," The Scientific World Journal, vol. 2014, Article ID 485820, , 2014.

[36] C. W. Cheung, J. F. Porter, and G. McKay, "Sorption kinetic analysis for the removal of cadmium ions from effluents using bone char," Water Research, vol. 35, no. 3, pp. 605-612, 2001.

[37] C. W. Cheung, J. F. Porter, and G. McKay, "Elovich equation and modified second-order equation for sorption of cadmium ions onto bone char," Journal of Chemical Technology \& Biotechnology, vol. 75, no. 11, pp. 963-970, 2000.

[38] S. M. Al-Garni, "Biosorption of lead by Gram-ve capsulated and non-capsulated bacteria," Water $S a$, vol. 31, no. 3, pp. 345-350, 2005.

[39] I. Langmuir, "The adsorption of gases on plane surfaces of glass, mica and platinum," Journal of the American Chemical Society, vol. 40, no. 9, pp. 1361-1403, 1918.

[40] R. Abdul, M. Tariq, A. Muhammad, R. Rabia, and B. Sumaira, "Usage of fruit-fibers of Luffa cylindrica for the sorptive removal of direct blue 15 dye from water," Desalination and Water Treatment, vol. 120, pp. 350-360, 2018.

[41] A. Bondarev, C.-G. Gheorghe, V. Gheorghe, and M. Bombos, "Removal of dyes from textile wastewater using sawdust as low-cost biosorbent," Revista de Chimie, vol. 71, no. 3, pp. 387-396, 2001.

[42] I. Ali, A. E. Burakov, A. V. Melezhik et al., "Removal of copper(II) and zinc(II) ions in water on a newly synthesized polyhydroquinone/graphene nanocomposite material: kinetics, thermodynamics and mechanism," Chemistry Select, vol. 4, no. 43, pp. 12708-12718, 2019.

[43] K. Fytianos, E. Voudrias, and E. Kokkalis, "Sorption-desorption behaviour of 2,4-dichlorophenol by marine sediments," Chemosphere, vol. 40, no. 1, pp. 3-6, 2000.

[44] S. Goldberg, "Equations and models describing adsorption processes in soils," Chemical Processes in Soils, vol. 8, pp. 489-517, 2005.

[45] M. Samarghandi, M. Hadi, S. Moayedi, and A. F. Barjesteh, "Two-parameter isotherms of methyl orange sorption by pinecone derived activated carbon," Iranian Journal of Environmental Health Science \& Engineering, vol. 6, no. 4, pp. 285-294, 2009.

[46] M. H. Jnr and A. I. Spiff, "Equilibrium sorption study of $\mathrm{Al}^{3+}$, $\mathrm{Co}^{2+}$ and $\mathrm{Ag}^{+}$in aqueous solutions by fluted pumpkin (Telfairia occidentalis HOOK f) waste biomass," Acta Chimica Slovenica, vol. 52, pp. 174-181, 2005. 
[47] C. Theivarasu and S. Mylsamy, "Equilibrium and kinetic adsorption studies of Rhodamine-B from aqueous solutions using cocoa (Theobroma cacao) shell as a new adsorbent," International Journal of Engineering, Science and Technology, vol. 2, no. 11, pp. 6284-6292, 2010.

[48] O. Çelebi, Ç. Üzüm, T. Shahwan, and H. N. Erten, "A radiotracer study of the adsorption behavior of aqueous $\mathrm{Ba}^{2+}$ ions on nanoparticles of zero-valent iron," Journal of Hazardous Materials, vol. 148, no. 3, pp. 761-767, 2007.

[49] C. C. Travis and E. L. Etnier, "A survey of sorption relationships for reactive solutes in soil," Journal of Environmental Quality, vol. 10, no. 1, pp. 8-17, 1981.

[50] M. Naushad, G. Sharma, A. Kumar et al., "Efficient removal of toxic phosphate anions from aqueous environment using pectin based quaternary amino anion exchanger," International Journal of Biological Macromolecules, vol. 106, pp. 110, 2018.

[51] M. Oladipo, I. Bello, D. Adeoye, K. Abdulsalam, and A. Giwa, "Sorptive removal of dyes from aqueous solution: a review," Advances in Environmental Biology, vol. 7, no. 11, pp. 33113327, 2013.

[52] B. C. S. Ferreira, F. S. Teodoro, A. B. Mageste, L. F. Gil, R. P. de Freitas, and L. V. A. Gurgel, "Application of a new carboxylate-functionalized sugarcane bagasse for adsorptive removal of crystal violet from aqueous solution: kinetic, equilibrium and thermodynamic studies," Industrial Crops and Products, vol. 65, pp. 521-534, 2015.

[53] T. Mahmud, "Biosorption of Auramine O and Drimarene dyes from aqueous solutions using seed powder of Diospyros lotus," International Journal of Environment and Sustainability, vol. 6, no. 3, 2018.

[54] S. S. Pillai, M. D. Mullassery, N. B. Fernandez, N. Girija, P. Geetha, and M. Koshy, "Biosorption of $\mathrm{Cr}(\mathrm{VI})$ from aqueous solution by chemically modified potato starch: equilibrium and kinetic studies," Ecotoxicology and Environmental Safety, vol. 92, pp. 199-205, 2013.

[55] A. Yargıç, R. Y. Şahin, N. Özbay, and E. Önal, “Assessment of toxic copper (II) biosorption from aqueous solution by chemically-treated tomato waste," Journal of Cleaner Production, vol. 88, pp. 152-159, 2015.

[56] M. Sahimi, "Characterization of surface morphology," Heterogeneous Materials: Nonlinear and Breakdown Properties and Atomistic Modeling, pp. 5-22, Springer, Berlin, Germany, 2003.

[57] H. Cui, A. Abu-Siada, S. Li, and S. Islam, "Correlation between dissolved gases and oil spectral response," in Proceedings of the 2017 1st International Conference on Electrical Materials and Power Equipment (ICEMPE), Xi'an, China, May 2017.

[58] J. Coates, "Interpretation of infrared spectra, a practical approach," Encyclopedia of Analytical Chemistry: Applications, Theory and Instrumentation, Wiley, New York, NY, USA, 2006.

[59] O. Segun Esan, O. Nurudeen Abiola, O. Owoyomi, C. Olumuyiwa Aboluwoye, and M. Olubunmi Osundiya, "Adsorption of brilliant green onto luffa cylindrical sponge: equilibrium, kinetics, and thermodynamic studies," ISRN Physical Chemistry, vol. 2014, Article ID 743532, 2014.

[60] F. Bouaziz, M. Koubaa, F. Kallel, R. E. Ghorbel, and S. E. Chaabouni, "Adsorptive removal of malachite green from aqueous solutions by almond gum: kinetic study and equilibrium isotherms," International Journal of Biological Macromolecules, vol. 105, pp. 56-65, 2017.
[61] M. A. E. Barakat, R. Kumar, M. K. Seliem et al., "Exfoliated clay decorated with magnetic iron nanoparticles for crystal violet adsorption: modeling and physicochemical interpretation," Nanomaterials, vol. 10, no. 8, p. 1454, 2020.

[62] Z. Rezayati Zad, B. Moosavi, and A. Taheri, "Synthesis of monodisperse magnetic hydroxyapatite $/ \mathrm{Fe}_{3} \mathrm{O}_{4}$ nanospheres for removal of Brilliant green (BG) and Coomassie brilliant blue (CBB) in the single and binary systems," Advanced Journal of Chemistry-Section B, vol. 2, no. 3, pp. 159-171, 2020.

[63] N. Laskar and U. Kumar, "SEM, FTIR and EDAX studies for the removal of safranin dye from water bodies using modified biomaterial-bambusa tulda," IOP Conference Series: Materials Science and Engineering, vol. 225, no. 1, 2017.

[64] N. Mohammadi, H. Khani, V. K. Gupta, E. Amereh, and S. Agarwal, "Adsorption process of methyl orange dye onto mesoporous carbon material-kinetic and thermodynamic studies," Journal of Colloid and Interface Science, vol. 362, no. 2, pp. 457-462, 2011.

[65] A. Mehmood, S. Bano, A. Fahim, R. Parveen, and S. Khurshid, "Efficient removal of crystal violet and eosin B from aqueous solution using Syzygium cumini leaves: a comparative study of acidic and basic dyes on a single adsorbent," Korean Journal of Chemical Engineering, vol. 32, no. 5, pp. 882-895, 2015.

[66] M. Choudhary, R. Kumar, and S. Neogi, "Activated biochar derived from Opuntia ficus-indica for the efficient adsorption of malachite green dye, $\mathrm{Cu}^{+2}$ and $\mathrm{Ni}^{+2}$ from water," Journal of Hazardous Materials, vol. 392, Article ID 122441, 2020.

[67] A. Chham, E. Khouya, M. Oumam et al., "The use of insoluble mater of moroccan oil shale for removal of dyes from aqueous solution," Chemistry International, vol. 4, no. 1, pp. 67-77, 2018.

[68] A. Gouza, K. Fanidi, S. Saoiabi, A. Laghzizil, and A. Saoiabi, "Effect of heat treatment on the surface properties of selected bituminous shale for cationic dye sorption," Desalination and Water Treatment, vol. 66, pp. 274-280, 2017.

[69] M. El Haddad, R. Slimani, R. Mamouni, S. ElAntri, and S. Lazar, "Removal of two textile dyes from aqueous solutions onto calcined bones," Journal of the Association of Arab Universities for Basic and Applied Sciences, vol. 14, no. 1, pp. 51-59, 2013.

[70] M. A. Barakat, R. Kumar, M. Balkhyour, and M. A. Taleb, "Novel $\mathrm{Al}_{2} \mathrm{O}_{3} / \mathrm{GO} /$ halloysite nanotube composite for sequestration of anionic and cationic dyes," RSC Advances, vol. 9, no. 24, pp. 13916-13926, 2019.

[71] R. Rehman, A. Abbas, A. Ayub, M. Salman, T. Mahmud, and U. Shafique, "Comparative study of Brilliant Green dye adsorption from water by radish peels, Jamun stem and coal," Electronic Journal of Environmental, Agricultural \& Food Chemistry, vol. 10, no. 7, 2011.

[72] J. O. Eniola, R. Kumar, A. A. Al-Rashdi, M. O. Ansari, and M. A. Barakat, "Fabrication of novel $\mathrm{Al}(\mathrm{OH})_{3} / \mathrm{CuMnAl}$-layered double hydroxide for detoxification of organic contaminants from aqueous solution," ACS Omega, vol. 4, no. 19, pp. 18268-18278, 2019.

[73] S. V. Mohan, S. Ramanaiah, B. Rajkumar, and P. Sarma, "Removal of fluoride from aqueous phase by biosorption onto algal biosorbent Spirogyra sp.- $\mathrm{IO}_{2}$ : sorption mechanism elucidation," Journal of Hazardous Materials, vol. 141, no. 3, pp. 465-474, 2007.

[74] V. Verma and A. Mishra, "Kinetic and isotherm modeling of adsorption of dyes onto rice husk carbon," Global NEST Journal, vol. 12, no. 2, pp. 190-196, 2010. 
[75] W. J. Weber and J. C. Morris, "Kinetics of adsorption on carbon from solution," Journal of the Sanitary Engineering Division, vol. 89, no. 2, pp. 31-59, 1963.

[76] M. C. Ncibi, B. Mahjoub, and M. Seffen, "Investigation of the sorption mechanisms of metal-complexed dye onto Posidonia oceanica (L.) fibres through kinetic modelling analysis," Bioresource Technology, vol. 99, no. 13, pp. 5582-5589, 2008.

[77] H. K. Boparai, M. Joseph, and D. M. O'Carroll, "Kinetics and thermodynamics of cadmium ion removal by adsorption onto nano zerovalent iron particles," Journal of Hazardous $\mathrm{Ma}$ terials, vol. 186, no. 1, pp. 458-465, 2011.

[78] A. Benmessaoud, D. Nibou, E. H. Mekatel, and S. Amokrane, "A comparative study of the linear and non-linear methods for determination of the optimum equilibrium isotherm for adsorption of $\mathrm{Pb}^{2+}$ ions onto Algerian treated clay, Iran," Journal of Chemistry and Chemical Engineering, vol. 39, no. 4, 2020.

[79] C. A. Igwegbe, O. D. Onukwuli, K. K. Onyechi, and S. Ahmadi, "Equilibrium and kinetics analysis on vat yellow 4 uptake from aqueous environment by modified rubber seed shells: nonlinear modelling," Journal of Materials and Environmental Science, vol. 11, pp. 1424-1444, 2020.

[80] J. O. Ighalo and A. G. Adeniyi, "Adsorption of pollutants by plant bark derived adsorbents: an empirical review," Journal of Water Process Engineering, vol. 35, Article ID 101228, 2020.

[81] M. Ali Khan, R. Govindasamy, A. Ahmad et al., "Carbon based polymeric nanocomposites for dye adsorption: synthesis, characterization, and application," Polymers, vol. 13, no. 3, p. 419, 2021.

[82] M. O. Ansari, R. Kumar, S. A. Ansari et al., "Anion selective pTSA doped polyaniline@graphene oxide-multiwalled carbon nanotube composite for $\mathrm{Cr}(\mathrm{VI})$ and congo red adsorption," Journal of Colloid and Interface Science, vol. 496, pp. 407-415, 2017.

[83] P. Liu, W. Liu, and Q. Xue, "In situ chemical oxidative graft polymerization of aniline from silica nanoparticles," Materials Chemistry and Physics, vol. 87, no. 1, pp. 109-113, 2004.

[84] M. Ghaedi, H. Hossainian, M. Montazerozohori et al., "A novel acorn based adsorbent for the removal of brilliant green," Desalination, vol. 281, pp. 226-233, 2011.

[85] V. S. Mane and P. V. Babu, "Studies on the adsorption of brilliant green dye from aqueous solution onto low-cost $\mathrm{NaOH}$ treated saw dust," Desalination, vol. 273, no. 2-3, pp. 321-329, 2011.

[86] Y. Kismir and A. Z. Aroguz, "Adsorption characteristics of the hazardous dye brilliant green on saklikent mud," Chemical Engineering Journal, vol. 172, no. 1, pp. 199-206, 2011.

[87] M. S. U. Rehman, M. Munir, M. Ashfaq et al., "Adsorption of brilliant green dye from aqueous solution onto red clay," Chemical Engineering Journal, vol. 228, pp. 54-62, 2013.

[88] R. Rehman, T. Mahmud, and M. Irum, "Brilliant green dye elimination from water using Psidium guajava leaves and Solanum tuberosum peels as adsorbents in environmentally benign way," Journal of Chemistry, vol. 2015, Article ID 126036, , 2015.

[89] S. O. Akpotu and B. Moodley, "Synthesis and characterization of citric acid grafted MCM-41 and its adsorption of cationic dyes," Journal of Environmental Chemical Engineering, vol. 4, no. 4, pp. 4503-4513, 2016. 